\title{
Data Base Research: A Survey
}

A. Blaser: H. Schmutz, IBM Wissenschaftiches Zentrum, Heidelberg, Tiergartenst $x^{2}=15$

\begin{abstract}
Abstrect
The reseerch ctivities in the area of data base systems are reviewed. Most of the issues considered by research institutes center around models of information, interactive data manipulation, system aspects, implementation techniques and modelling and analysis. Comparison with industry activities and documented user requirements shows differences of emphasis between research and development. Conclusions are drawn with respect to established and potentially emerging principles in the area of data base design and architecture and with respect to potential future trends in data base research.
\end{abstract}

\section{TAPLE OF CONTENTS}

1. Introduction

2. Data Models

3. Data Manipulation languages

4. System Problems

5. Storage Structures and Search Algorithms

6. Modelling and Analysis

7. Summary and Conclusions

8. Bibliography

1. INTRODUCTION $\& 9,192 \%$

The abjective of this paper is primarily to provide an overview over past end present resexch activities in the data base area. This pa- 
per does not survey commercially available data base software. Further, information retrieval systems and non-computeroriented aspects of information systems are not addressed. We are well aware of the danger of such $11 \mathrm{mitations}$ and recommend to the reader, who is interested in an introduction to the field, to study in ciepth some of the commercially avallable data base systems, such as IMS (A.J. Barnett and J.A. Lightfoot: Information Management System (IMS) - A Users Experience with Evolutionery Development. In Data Base Management Systems (D.A. Jardine editor), North Holland, Amsterdan, 1974) in addition to the 1iterature ceferenced in this survey.

What is a data base system? This is already a question, which has been and still is subject of debates. We will make our definition with the help of a scheme, which in our experience is widely accepted. It is a simplification of an architecture scheme employed by a major standardIzation group (ANSI/X3/SPARC) and is very similar to schemes shown in Date's or Wedekind's book. To the authors knowledge, the IMS designer have been the first who implemented, consciously or unconsciously, such a scheme nearly a decade ago.

The scheme is shown in fig. 1 and shows persons, views of information, data mappings, programs and a data flow during retrieval of information. The conceptual view is the central point. It represents the way information is seen by the group responaible for the system aspects of stored, integrated information. This group is usually referred to as the "data base administrator". For a given system installation, a conceptual schema specifies which type of information may exist at the conceptual level. A schema describes, what is legal or "correct" and is therefore similar to a grammar defining the syntax of a language.

The conceptual view is never used directiy. It serves as a centrai reference point for other views of information. For example, the physical or internal view of information reflects the way the information is actually stored in memory. Given the data base in conceptual form, we can construct the corresponding physical form with the help of a mapping, the conceptual to internal mapping (fig. 1 mapping C/I).

The use of conceptual information is through mappings. All of these mappings are in the responsibility of the data base administrator and are specified in a data definition and maping language. The mappings between conceptual and external views serve a double purpose: (a) to select the subpart of information necessary and sufficient for a spe- 


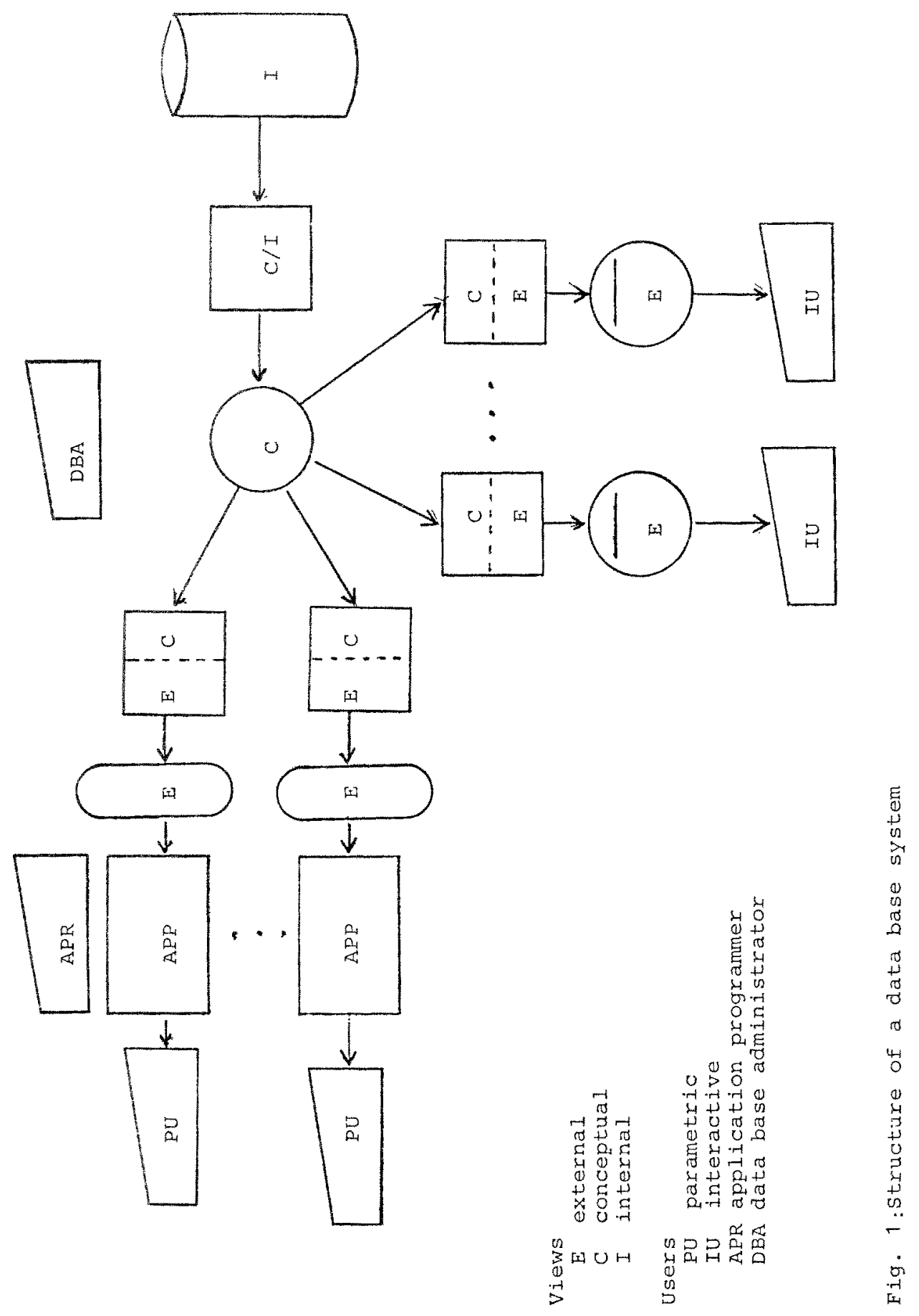


cific use of the data base and (b) possibly, to transform the selected subview to a view, which is "more natural" for the specific use. point (a) represents the primary purpose and is of importance for reasons of protection, scheduling, user isolation etce, i.e. essentially for systems aspects.

There are two major end-user groups to consider. First we have the query language user, also called the interactive problem solver and typified by the "non-DP-professional". The query languege users view of data is very similar to the conceptuai view. He performs data manipulation at a fairly high level without needing help by experts. This is different for the "parametric user", who performs well defined actions with parameters of a simple structure. This user interacts ith the system via application programs written by application programers in some programing language into which a data manipulation language is Incorporated as a sublanguage. We talk of a host language - sublanguage relationship. In general, the query data manipulation language is at a higher level than the application programmers data mantpulation language.

In practice, large amounts of stored information are extremely unlikely to be used by only one person. It is therefore a requirement to a data base manegement system that it allows sharing of and concurrent access to the stored information. Concurrency creates a number of problems in connection with system integrity, scheduling, deadlock prevention, recovery, protection, and efficiency in solving all these problems.

While commercially employed systems (1ike IMS) p-imarily support applications involving parametric users, research concentrates on support of the interactive problem solver. Correspondingly we find a large number of research activities oriented towards the data model used for the conceptual view and to a single user high level query language system. Sections 2 and 3 are devoted to data models and data manipulation languages to describe this research. In section 4 we wil discuss research in the area of system aspects. Section 5 describes contributions of research to implementation techniques such as a storage structures and search algorithms. Section 6 will refer to some of the modeling, neasurement and analysis efforts and section 7 will contain conclusions with respect to primary results, recognizable trends and some major problems deserving research. 
The conceptual view has been introduced as the central point of reference in a data base management system. Clearly, such a view should be as close as possible to intultive notions ot information. Proposals for a conceptual view are known as data models. A conceptual data model provides a set of possibilities of how to encode conceptually intormation which exists in the real world. Of course, the mapping between real world information and conceptual information is not formalized.

Closely connecter fith the notion of a conceptual data model is that of conceptual schema. For illustration purposes let us consider an extremely simplified real world situation. We have sets p of professors, $s$ of students, and $c$ of courses. Each of the objects in these sets has a numer, which is unique within the set, and a name. Further, we know for every professor which students he advises and which courses are tought by him. A student has exactly one professor as advisor and may attend a number of courses and a course is taught by exactly one professor and attended by a number of students. Fig. 2 shows the information in an attempt to be close to reality without biasing towards any data model.

Conceptual data models are all more or less based on the notions of set theory. One of the earier attempts is the Information Algebra of CODASYL /34\% other models and stimulating ideas are due to Mealy /124/, Feldman and Rovner /74/, and, Ash and Sibley/3/. The most successful model in terms of acceptance and as a stimulus for data base research has been developed by E. F. Codd in a series of papers to which we will devote the next subsection.

2.1. Codd's Relational Model (CRM) $/ 39-41,43 /$

In CRM information is finite set of named relations of assorted deeree. A n-ay relation is a finite subset of a cartesian product

$$
D 1 \times D 2 \times \ldots D n
$$

where the $D i$ are potentlally intinite sets of "scalarll data values such as numerical values or string values. In other words, a n-ary relation if a set of n-tuples. To any relation, the elements of the 

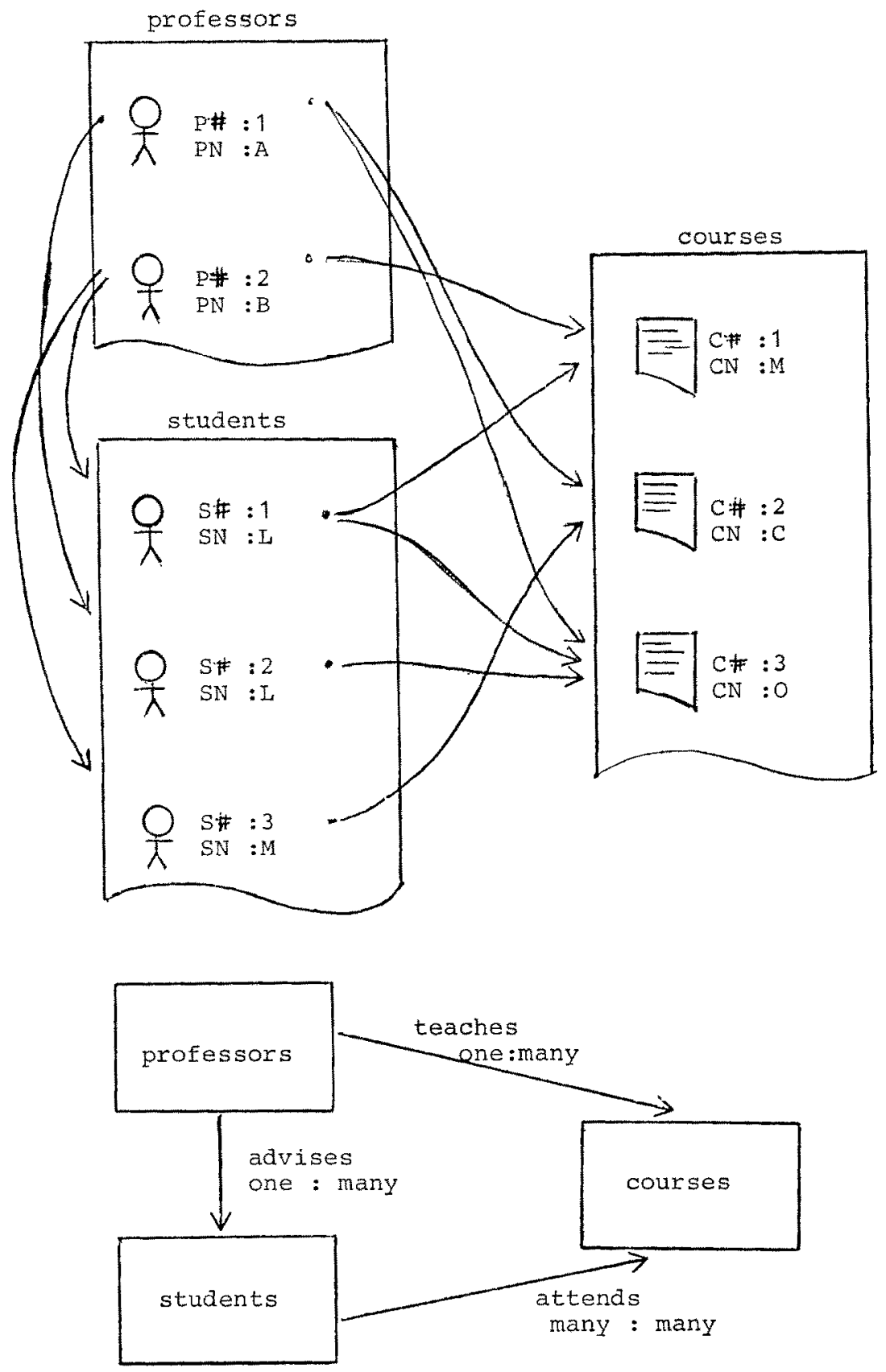

Fig. 2:Example situation and schema 
tuples are named with attibute names for ease of reference. A relation is homogeneous, i.e. any two elements of the same relation have the same attribute names associated with them. This allows a tabular listing of a relation as shown in fig. 3 , the representation of the example information in CRM.

Some domains within a relation may be keys and/or references. Two distinct tuples in a relation have different values in their key elements. A refernce domain actually is used to refer to some value that is element of another tuple in the same or another relation. For example, P\# in $P$ is a key domain, but $P \#$ in $S$ is a reference domain which contains only such integer values, which appear as P\# in P.

The relations shown in 1 ig. 3 and corresponding to the schema indicated in fig. 4 axe all in socalled first normal form. Inis means, that all elements of a tuple are scalar land not sets or lists or structural in any other wayl. This has consequences in the way information can be modeled. Consider the relationship between sturents and professors. Principally there are at least two ways to store this information:

(a) we can build the set of all students (or their unique numbers) advised by one professor and store this set with the professor tuple or

(b) we store with every student the professor for his unique numberl, which advises the student. Case (a) would not be in lifist normal form". Fortunately, case (b) is in this form.

The relationships between professors and students or professors and courses are one to many (i.e. one professor advises many students). In these cases we store the converse relation to satisfy normalization. However, the student/course relationship is many to many and therefore requires the introduction of an additional relation, the relation SC. Codd has defined further normalizations, the "secona" and "thifd normal form", which essentially serve to remove some redundancies. The reader is referred to Codd $/ 41 /$, Date $/ 49 /$, or Wedekind $1192 /$.

The advantages of CRM are its apparent simplicity and its appeal to those, who are used to "think" in tables, in particular for researchers with a background in the elementary notions of discrete mathematics. Since a relation 1 s a set, set operations like union, intersection, relative complementation etc. can immediately be applied if the relations agree in domain names. More importantly, projection may be 


\begin{tabular}{|c|c|c|}
\hline \multicolumn{2}{|c|}{$S$} \\
\hline$S H$ & $\mathrm{SN}$ & $\mathrm{PH}$ \\
\hline 1 & $\mathrm{~L}$ & 2 \\
2 & $\mathrm{~L}$ & 1 \\
3 & $\mathrm{M}$ & 2 \\
\hline
\end{tabular}

\begin{tabular}{|c|c|}
\hline \multicolumn{2}{|c|}{$P$} \\
\hline$P \#$ & $P N$ \\
\hline 1 & $A$ \\
2 & $B$ \\
\hline
\end{tabular}

\begin{tabular}{|c|c|c|}
\hline \multicolumn{3}{|c|}{$C$} \\
\hline$C H$ & $C N$ & $P \#$ \\
\hline 1 & $M$ & 2 \\
2 & $C$ & 1 \\
3 & $O$ & 1 \\
\hline
\end{tabular}

\begin{tabular}{|c|c|}
\hline \multicolumn{2}{|c|}{$S C$} \\
\hline$S \#$ & $C$ \\
\hline 1 & 1 \\
1 & 3 \\
2 & 3 \\
3 & 2 \\
\hline
\end{tabular}

Fig. 3: Normalized CRM relations

$S$ (S\# int, $S N$ char, $P$ int) key (SH) ref (P\#to P.PH)

$\mathrm{P}$ (P* int, $\mathrm{PN}$ char) key (P\#)

$C$ (C\#int, $C N$ char, $P \#$ int) key (C\#) ref (P\# to P.P\#)

SC (S\# int, C\# char) key (S\#, CH) ref (S\# to S.SH, C\#to C.CH)

Fig. 4 CRM schema 
applied to relations and relations of different structure may be combined using well known methods of composition such as cartesian procuct or pierce product, or a generallzation called join in Cadd"s terminology. In a sightly different approach every relation may be viewed as a stored predicate and finst order predicate calculus may be applied to define new relations. Cadd has investigated both approaches, the "relational algebra" and the "relational calculus" and has shown that they are equivalent $/ 41 /$.

The relational model has been subject to a number of critical considerations $/ 20,43 /$. It $1 \mathrm{~s}$ obvious that it does not offer the full range of structures to which we are used within computer science. It has, for example, no equivalent to the hieracchic record organization of COBOL, PL/I, PASCAL or ALGOL68, a structure which is simple, corresponds to intuition and is most frequently used. This is only one important example of a structure violating the "first normal form" condition.

The example of the relatonship between students and professors has shown how the schema is affected by constraints. For example, if the one:many constraint of the professor - student relationship is relaxed to a many:many constraint, completely new relation has to be introduced.

Another consequence of nomalization is the fact, that basic information has to be encoded wth the help of other information, which is ofter of no interest to the requestor of the basic information. For example, in order to know the name of the advisor of the student with name "M", the "system" has to learn that this advisor has the professor number 2, since there is no other way to get to his name. This may be considered tolerable, however, more critical situations arise, if we allow a user to see only a subset of domains, which does not contain the key ralues. For example, a particular user may be allowed to look at every employee's salary and compare it with the employee's manager salary, but for reasons of privacy he is not allowed to look at the man numbers associated with the salaries. There are immediately two problems. First, in order to find a man's manager's salary, the user has to know the man number of this manages, contradicting the privacy constraint. Second, if the man number is projected out it may well happen that two persons with the same salary appear as one tuple in the projection thus making any statistics on salary distribution in the projection invalid. One can imagine ways around the first prob- 
lem though no elegant ways are known to the authors. The second problem is solved in at least some of the experimental systems (like INGRES, SQUARE) by allowing "duplicates in sets". These implementations are actually implementing a homogeneous flat file model as it is described, for example,

by NcGee /122/. This model is in turn a special case of the graph model described later in this section. It cannot be claimed that implementations of the homogeneous flat file model find their clean, theoretical foundation in CRM, though some operations, Ilke joins, make sense with both kinds of data structures.

\subsection{Graph Oriented Data Models}

The common idea behind the data models discussed in this section is the implicit or explicit notion of labeled graphs over entities or named binary relations between entities. The orlgins of the model in computer science goes back to McCarthy"s abstract objects fas models of information) which have to conform to an abstract syntax (as the schema to the nodel). (McCarthy,J.: Towards a Mathematical Science of Computation. Proc. IFIP Congr. 1962, North Holland, Amsterdam, 1963$).$ McCarthy's work has influenced the activities of a group in the IBM Vienna Laboratories to model the interpreter states during execution of programs (Lucas $P$. and $K$. Walk: On the formal description of $P L / I$. Annual Reviews of Automatic Programming 6, 3 (1969)). The data structures in languages like COBOL, PL/I, PASCAL, and ALGOL68 are adaptations and extensions of this model, in general with restrictions as to what may be specified in a schema. "Schema" appears now as a synonym for "declaration" or "abstract syntax". Some of the data models designers refer explicitely to this origin /1, 56/. Practically all commercially available data base systems are based on the graph model.

Within data base research activities the graph model shows up more or less consciously in a number of pepers. McGee discusses a graph model in $1968 / 121 /$. The entity set model of the DIAM system designed by Astrahan, Altman, Fehder and Senko is essentially a binary relational model and therefore a graph model/155/. Other well known graph models are those developed in CODASYL activities and generally known as the DBTG model $/ 35,37,38 /$. We find the graph model also in Abrial's "data semantics" $/ 1 /$ and many other research papers $/ 20,56,63,158 /$. Schmid and swenson employed recentiy some sort of graph model to es- 
tablish a connection between relations in CRM and the real world $151 /$.

Among the earliex data base research activities the DIAM effort deserves special attention /155/. It contributed essentially to the acceptence of a data base system structure as shown in fig. 1 . Its data model, the entity set model, had and still has impact on standerdization activities. The DIAM data model has not been defined with the same mathematical rigor as CRM. This is related to the fact, that its designers stressed the closeness of the nodel to the real world more than pure mathematical formalism. We will not discuss the DIAM model In more detail here since it can be rapped in a straightforward way to the subsequently described graph model and as such find a clean mathematical foundation.

The essential notion of the graph model is thet of an abstraction of objects as nodes in a graph. To be consistent with the most frequently used terminology we call such a node an entity. An entity may be anything "that has reality and distinction of being in fact or in thought, e.g. objects, associations, concepts, and events" /34, $155 /$. Some entities have unique denotations like

5,7 or ABCP. Other types of entities can only be uniquely identified with the help of relationships between entities.

Information in the graph model is stored as a finite set of named finite binary relations between entities. Since entities are nodes in a graph, relations can be represented as directed labeled edges in the graph. To represent unary relations (which are sets of entities) we assume a given node as the entry node to the information and interprete the binary relation between entry node and any other node as a unary relation. For simplicity in drawing a graph we represent edges frow the entry node to other nodes by labeling these nodes with the relation name. Fig. 5 and fig. 6 show the graph model representation and schema for our example.

A first advantage of the graph model over CRM is the fact that only binasy relations are used. This removes the need to distinguish between the domains yia symbolic domain names. More importantly, due to its explicis notion of entities, which is not present in CRM, it is clean and cleax in the mathematical sense without the need to dewiate from it for "practical" reasons of convenience. Like for CRM, 1 is possible to develop calculus or algebra oriented languages with the 


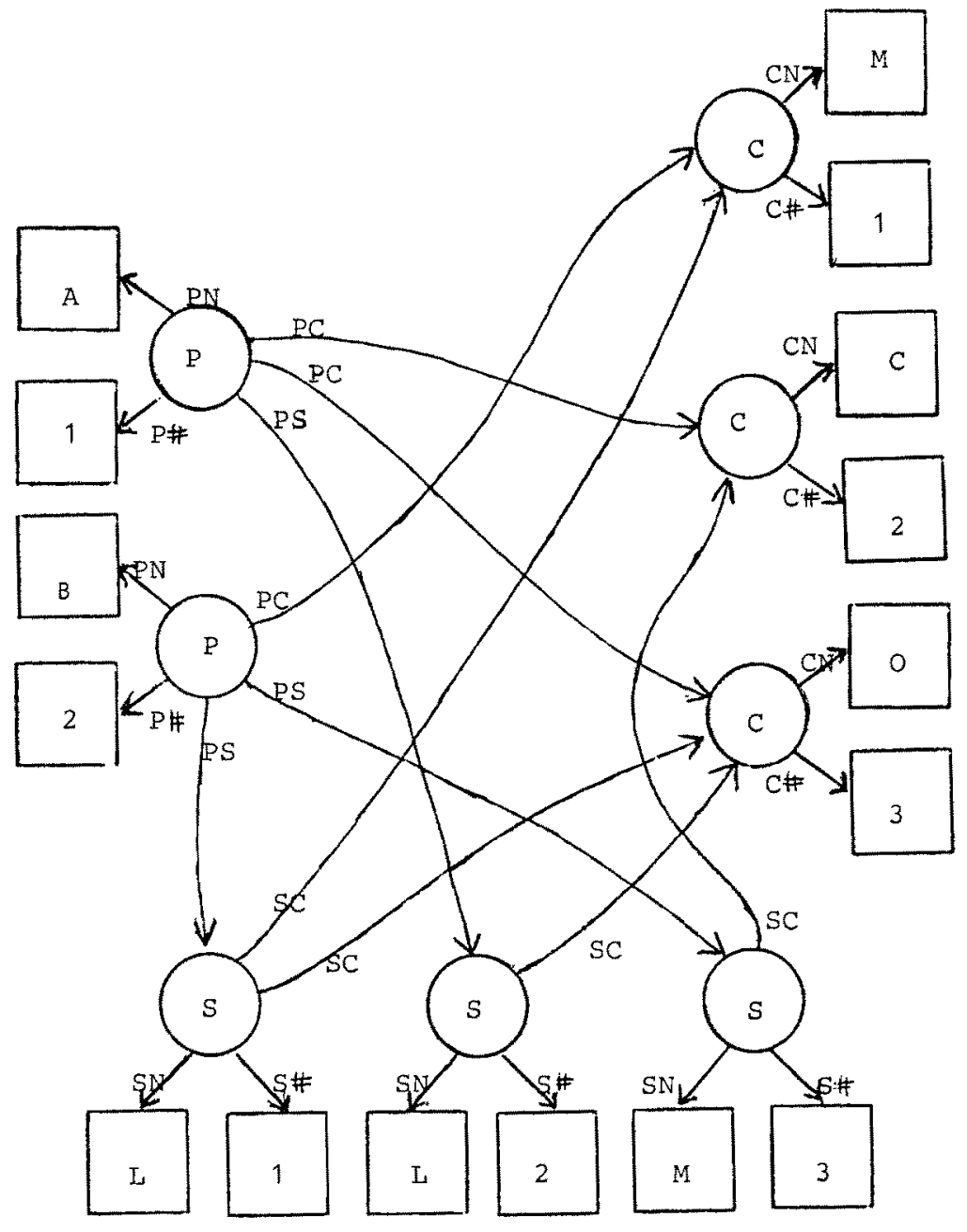

Fig. 5 :Information as a graph 


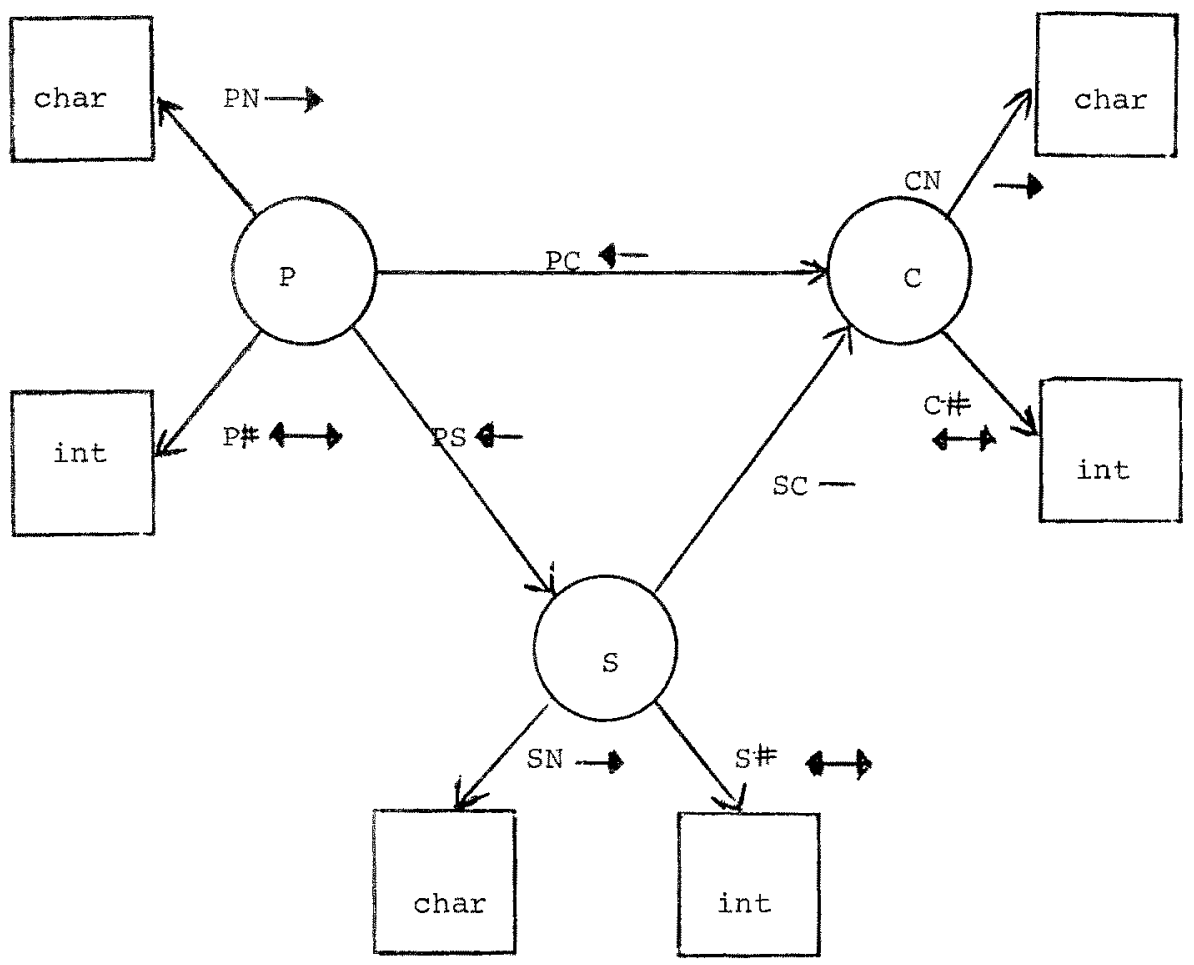

$\mathrm{R} \rightarrow$ one: one

$\mathrm{R} \rightarrow$ many : one

$\mathrm{R} \&$ one : many

$\mathrm{R}-\operatorname{many}: \operatorname{man} y$

Fig. 6: Schema to the graph model 


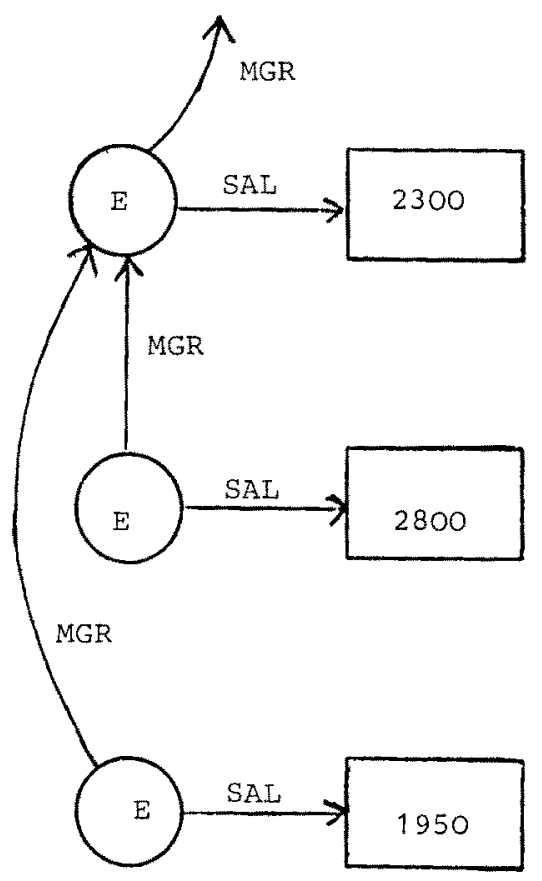

Fig. 7: Subgraph of E, MGR and SAL 
same sigor /128/. On the other side it does not provide difficulty to furnish a user with a subview of the data base (i.e. a subgraph) which restricts to the relationships, which may be seen by the user. see fig. 7 for an lilustration. Since practically all known structures in computer science can be mapped conveniently to some form of graphs, it does not force us to exclude these structures from our high level data modeling.

\subsection{The Equivalence of Data Models}

It is not at all surprising that the different models are equivalent in the sense that information encoded in the DBTG or DIAM model can be encoded in CRM and vice versa. Moreover, in most cases there is a simple and straightforward way to convert a schema in one model to a corresponding equivalent schema in the other. The question of choice between two different models must be decided on how "convenient" or "natural" processing becomes in the models. This is, however, not only a question of the data modej but also a question of the data manipulation language. In the next section we will therefore come back to the question of equivalence.

The question of equivalence of data models has been investigated by Bobrow /17/, Neuhold /134/, Sibley /167/ and Molee /122/. Different models are likely to coexist for a while lat least in the world of researches), even on the same system. This creates a new mapplng problem, namely of how to superimpose a model A on a madel $B$, a problem, which creates he need for a "superimposition theory" as it was stated by E.F. Codd $/ 43 /$. First results in this direction are reported by Frasson $/ 82 /$.

\section{DATA MANIPULATION LANGUAGES}

\subsection{Low Level Versus High Level Logic}

As we can see in $f$ ig. 1, data are accessed in external form either via an application program or interactively at a terminal. In the first case, recorts are typlcally retrieved one by one and processed sequentially in a programming language. This type of processing is referred to as "low level" or as "one record at a time logic". Typical for the second case of access is the higher level "multiple records at a time 
logic". Research activities are primarily oriented towards the higher level logic. It is important to realize that also in the application program case "multiple records at a time logic" is required to specify in advance on which subset of the data the program is going to operate. The system needs this information for scheduling and resource allocation purposes. In effect, the selection of the subspace to a program is a mapping between the conceptual and the external view, which by the nature of its use has to be specified in a high level logic. Even though research projects are primarily oriented towards interactive access to data and even though their implemented systems are modest compared to commercially available systems, their results may very well be of relevance for the type of processing through application programs as it is still more common in todays user installations.

Subsequently some of the data manipulation languages developed by researchers will be referenced. We start with the CRM implementations, then we continue with languages based on other data models. A special subsection is devoted to languages which are characterized by the way in which they are used. Finally we will come back to the equivalence of data models.

\subsection{Some CRM Implementations}

Table I lists some of the experimental systems, which claim to implement CRM, though for some it would be more correct to claim that they

System

IS $/ \mathrm{I}$

MacAins

RDMS

MORTS

SQUARE

SEQUEL

INGRES

ZETA

DAMAS location

IBM UK

MIT

MIT/MULTICS

Milano

IBM Research

IBM Research

Berkeley

Toronto

MI T remark

$\begin{array}{ll}\text { algebra } & \text { Todd } \\ \text { algebra } & \text { Goldstein } \\ \text { algebra } & \text { Steuert } \\ \text { calculus } & \text { Bracchi } \\ \text { mapping } & \text { Boyce } \\ \text { mapping } & \text { Chamberlin } \\ \text { calculus } & \text { Held } \\ \text { definitional } & \text { Mylopoulos } \\ \text { calculus } & \text { Rothnie }\end{array}$

Table I. Some relational systems 
implement homogeneous flat file. of the nine systems shown, the first four represent early experiments. SQUARE is a language based on the concept of "mapping", an approach which is somewhere in between relatonal algebra and relational calculus. It is implemented on top of XRM, a data management supporting n-ary relations or, better, homogeneous flat files /111/. XRM in turn is implemented on top of RAM, a data management, which supports stored binary relations and resembles the graph model /110/. SQUARE has a compact syntax. The query languape SEQUEL is derived from it with more English keywords. INGRES stands for a system, which offers QUEx and the graphics oriented CUPID as enduser interfaces /93, 119/. ZETA is a system which is currently being developed at Toronto. It has a data management supporting relations and provides a "syntax directed" definitional tool to let the user 1 mplement his high level query language on top of low level primitives. DAMAS is a system specifically used by its implenentor to study an optinization aspect of data access.

To give an impmession of the different styles of query languages let us consicter the following query:

What is the name of the arvisor of the student, whose name is "Mn?

In IS/1, the relatonal algebra approach, we obtain:

$$
(1 * * \mathrm{~s} ; \mathrm{C2}=\mathrm{M}) 1) \mathrm{C1}=\mathrm{C5}) \% \mathrm{C} 2
$$

This expression is a sequence of a selection (operator $=$;), a cartesian product (operator $=* *$ ), a second selection and a projection (operator $=\%{ }^{*}$ ). Ci refers to the value in the i'th domain.

In QUEL, the calculus oriented query language to INGRES, we obtain:

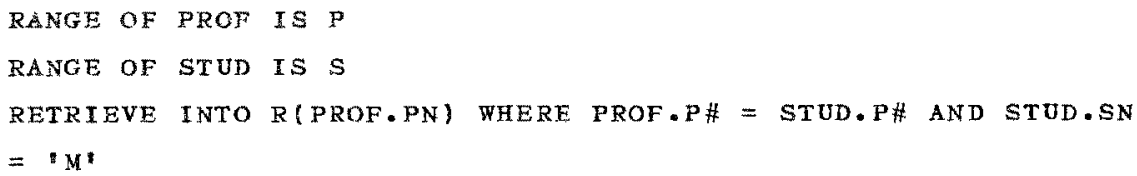

Here the answer is in the result relation $R$, a unary reletion. Clearly PROF and STUD are variables in the predicate calculus sense over which existential quantifications are applied by default. 
In SEQUEL, the "mapping" approach, we obtain:

\author{
SELECT PN FROM P WHERE P.P\# IN \\ SELECT P\# FROM S WHERE $S . S N=' M '$; ;
}

A11. of the nine systems represent what might be called first eneration research data base systems. This means that their contribution to the solution of data base problems, though already significant as pointed out above, may be increased by follow-on development. At least for the three systems SEQUEL, INGRES, and ZETA we know that such ongoing research is planned. The follow-on system to SEQUEL is called System R.

\title{
3.3. Some Non-CRM Systems
}

As already mentioned, most research activities are using cRM as their data model. In this subsection we will discuss some languages which are using a graph oriented data model.

First there is DIAM with RIL (Representation Independent Language) as its data manipulation language /72/. The DIAM work continues in an effort called DIAM II with FORAL as its query language/157-159/. Senko's FORAL has the interesting property of a graph lor binary relationall model oriented query language for the composition of relations between entlies. The example query of the preceding subsection can be formulated in FORAL as follow:

$$
P(P N) \text { where for PS } S N=' M \text { '; }
$$

FORAL establishes the connection between professors and students with a single identifier where IS/1 or QUEL need at least one comparison. A recently described system, developed in Nice, implements the graph model on top of I IS and offers a query langusge with similar advantages $/ 82 /$. McGee describes a data manipulation language to a conceptual graph model, which is very similar to the DBTG model $/ 123 /$.

A very interesting research developed system is SrMs/194/ which offers a query language and a data definition language. The data definition language allows to map data given in their internal form and possibly generated on another computer, to a hierarchical conceptual form. This hierarchical form can then be accessed by the query lan- 
guage without actually converting the data. SIMS neets with these features objectives, which are issed by mast other experimental systems, though SIMS is one of the earlier lmplementations.

Report generation, ise the design of layouts of computer generated reports ls a non-trivial problem which to solve with the help of a computer seems natural. Dana and Presser report about an interesting hlgh level language speclfically designed for this task /46/.

\subsection{User Interface Aspects}

In this section we will discuss some data manipulation languages whose deslgners apply a specific technique ith respect to the interface to the user.

A sexies of reseasch efforts has as 1 ts target to embed the query language into a general purpose programming language to combine the data access with powerul computational facilities. Two of these efforts have as their specific esearch goal to develop and study protection mechanisms $144,75 /$. Earley describes a proposal for the inclusion of CRM data structures into an ALGol like language/59/. Schauer proposes to build an interactive CRM query language in a tata base system for the evaluation of measurement data on top of APL /149/.

A question, which is currently still open, is whether the traditional way of defining rigocously a formal language is the best way to attract all end-user groups to the computer. Some researchers believe in the possibility that a freedom in syntax as offered by a natural laneuace, might make the computer more attractive to at least some user groups. Codd proposes such a natumal language system, called RENDEZvous, which is currently being implemented /42/. TORUS is a natural language system being developed at Toronto. It uses zETA as its data manazement /131/. Thompson, Petrick and Kraegeloh report about experlmental language systems, which are already implemented /184, 147 , 102\%. Further references to systems natural language and the 1 ingulstic approach can be found in $/ 156 /$.

The feasibility of the "communication ith the computer in natural language" is subject to rather sceptical considerations. In the case of data manipulation languages many of these considerations are not applicable, since the "universe of discourse" is essentially restrict- 
ed to the objects and verbs stored in the data base and described in a simply structured data dictionary.

A completely different appoach is taken by zloof, McDonald and Schauer / $198,119,149 /$. Thelr method requires a display device, which is used to display the description of the stored CRM relations in some graphical form. In Zloof's Query By Example the user fills "examples" into free spaces of the relation description. simple queries can be formulated easily and with a low probability of error. In McDonaldis CUPID, the user has to draw a flow diagram Iike plcture ( with the help of a menue $/$ which expresses the semantics of the query. Schauer's extended query by example is an extension and morification of zloof's method. It is natural to use a display device if information is assoclated wth geographic locations. GADS $/ 25 /$ is such a system in which a user can point to locations or subareas within a displayed map to obtain information related to the graphic entities.

The question, wether one user-interface oriented approach is more successful than another cannot be answered by abstract reasoning. Investigations are under way, which employ the methods of experimental psychology to find unbiased answers to the posed question /143, $183 /$. One of the reported experiments seems to indicate that questions of syntax (or more generally of the form as opposed to the contents) are of a slight signiflcance for the unskilled while questions of semantics are significant independent of the users skill /143/.

\subsection{Data Mode1 Equivalence}

As pointed out earlier, and illustrated by examples, we know that different data models are (or "can be made") equivalent with respect to corresponding schemata. Subsequently we will briefly indicate that equivalence can easily be extended to the equivalence of the query languages. To this end we introduce informaliy two query languages, one (CRM) for CRM and the other (GRAPH) for the graph model. Both languages are very siml lar to SEQUEL. In CRM we deal with relation names, attribute names and variables. A variable is denoted by a relation name followed by a period followed by an attribute name. 
Example

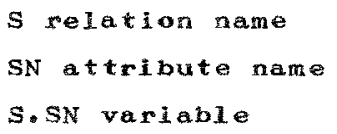

In GRAPH we deal with sets (unary relations) and relations (binary relations). A set denotation is a set name or a set name followed by a period followed by a relation denotation. A relation denotation is a relation name or celation name followed by a period followed by a celation denotation. A set denotation may also be used as a variable with the obvious meaning thet the variable "rung" over all elements of the set.

Example

$$
\begin{aligned}
& \text { S. } 5 . S C, S . S C . C N \text { sets (or variables) } \\
& \text { PS, PS.SC, PS.SC.CN relations }
\end{aligned}
$$

It should be noted that GRAPH is recursive in the definition of sets while CRM is bound to two levels.

The period is in both languages used as the operator for functional composition prom left to right.

A query is of the form:

SELECT 1 ISt 1 FROM IIst2 WHERE predicate;

In CRlf listi is a list of atribute names, list2 is a list of relation names, and the predicate is over variables which can be built starting with the relations in 1 ist2.

In GRAPH listi is a list of relation denotations, 1 ist2 is a list of set denotations and the predicate is over set denotations which can be built with the help ot relations starting with the sets in list2.

In both languages the use af subseripts may be necessary to evold ambiguity. The subsequent examples are such that ambiguity does not arise. 
Query 1

Name of the professor, who advises student $M$.

CRM:

SELECT PN FROM P,S WHERE P.P\# = S.P\# and $S \cdot S N=" M '$;

GRAPH

SELECT PN FROM P WHERE P.PS.SN $=$ 'M'

This simple query illustrates already the essential difference between the two data models. CRM normalization requires that some logical relationship between entities are encoded with the help of unique porperties of these entities while in the graph model these relationships may be used directly. Therefore, CRM has to make a comparison where GRAPH simply uses functional composition as we do in natural language. This will become even more apparent in the next query.

Query 2

Names of courses attended by students which are advised by 'B'.

CRM :

SELECT CN FROM P, S, C, SC WHERE P.PN $=1 \mathrm{~B}^{*}$ and $P . P \#=S . P \#$ and $\mathrm{S} \cdot \mathrm{SH}=\mathrm{SC} \cdot \mathrm{S \#}$ and $\mathrm{SC} \cdot \mathrm{CH}=\mathrm{C} \cdot \mathrm{C \#}$;

GRAPH:

SELECT PS.SC.CN FROM P WHERE P.PN $=" B:$;

The brevity and elegance of the GRAPH form compared to the CRM form should, however, not be used to conclude an essential superiority of the graph model over CRM. In fact, it is possible to extend the CRM language with a macro processor which accepts as definitions relations between entities in terms of their CRM encodings. This macro processor can then accept GRAPH queries and convert these queries into CRM querles in a simple straight forward algorithm. With other words, we can implement the GRAPH language on top of a CRM implementation such that the user has all the advantages of the graph model. The differences 
of the languages and their underlying models appear on level phich is primarily of a syntactical nature since they can be transformed away with the help of syntax macros. Issues of one data model versus the other are of litle practical relevance given the right sort of implementation. Many other questions like those discussed in subsequent sections deserve and are in the process of receiving more attention.

\section{SYSTEM PROBLEMS}

\subsection{Introduction}

The major problems $z^{n}$ a data base system like IMS are connected with concurrent access to data shared by many users, with application program management and scheduling, with system enforced data integrity, with locking and ceovery or error isolation, with data independence and last, but not least, with high enough transaction rates and short enough response times to make the whole system attractive for the user.

The implementation of such a system, even for experimental purposes, may turn out to be quite costly in time and manpower. It 1 s therefore natural that only few research projects aim at a large portion of the full set of data base management system functions. Among the systems mentioned in section 3 , DIAM in 1 ts original conception was at least very ambitious with respect to data independence and supported storage structures. System R, the follaw-on activity to SEQUEL, though belne experimental, plans to provide solutions in nearly all of the problem areas mentioned above.

The fact that researchers so far have not developed full size operational data base systems does not mean that they have ignored problems outslde data models and high level query languages. In subsequent sections we ill reference a considerable number of relevant paoers in the area of data independence and data integrity and recovery in connection with multi-user systems. In addition, the reader will find references to research in the area of security and authorization in the attached bibliography. 


\subsection{Data Independence /175/}

A data base system supports data independence to the extent in which it allows transformations of the internal or conceptual forms of data without affecting (a maximun of) existing programs in the sense that non-affected programs, which run correctly before the transformations, run also correctly after the transformations. Hence, data independence is in effect the independence of programs with respect to data transformations. This makes clear that data independence is not the automatic consequence of the selection of a certain conceptual data model as it is sometimes claimed.

We distinguish between internal and conceptual data independence. The need for internal data independence, i.e. Independence of application programs with respect to changes of the internal form of the data, while the conceputal form stays invariant, is a consequence of the widely recognized fact that there is no absolutely best internal data organization /182/. The performance of an application program depends heavily on how many of its access paths are directly implemented (tor example via links or inverted files or other storage structures; see section 51. Every such direct implementation means redundancy in storing, $1 . e$. requires additional update activities. The data base administrator will attempt to optimize the internal organization for a given mix of application programs. Since the mix changes with time, there w11 be a need to adapt the internal data organization.

The need for conceptual data independence arises due to additions of new types of information, or more generally, changes in the conceptual schema. In general, at least some of the existing application programs are affected, while still a large part may remain unaffected. Consider, for example, the addition of a domain to a CRM conceptual data base. There should be no need to alter programs, which only read data, since the old model is a subview (projection) of the new model. This may already be different for programs which update information, since there may be a dependency between the changed domalns and the new domain. Certainly, at least some of the programs which insert new elements into relations are affected, since otherwise the new information cannot be entered. other changes in the conceptual model, for example, relaxing the many to one constraint of a binary relation to a many to many constralnt, may even affect read only programs, if these programs are designed such, that they rely on the old many to one constralnt. 
Support of conceptual data independence requires that the system is capable of determine for each of its application programs, whether it is affected or not. Thls involves a very complex decision problem, which is not solvable in general. It is therefore necessary to restrict the date mapping languages such that the decision problem rem mains solvable. This requires a type of theory, which has not been extensively applied fexceptions eppear, in other contexts, in 53 and $65 /$.

Support of internal data independence requires the foliowing:

1. data definition and mapping language, which specifies the internal form to every conceptual formallowed by the schema. The degree of data independence to a given conceptual schema is the get of different mappings supported for the conceptual schema.

2. To any given application program the system must be capable of recognizing the predefined access paths in the internal schema, which neet "optlmally" the program's needs, and exploit these access paths during execution of the program. rhis process has been called reduction of the external access to the internal access. A system without this optimizing reduction may be "logically" data independent but practically serves no purpose. In other ords, what is necessary is a data independence which results in performance gains for the user.

Almost all of the experimental query language implementations described in section 3 support data independence to a 1 inted degree in the fallowing way: When a user fin his "data base administration role") introduces a new relation he may specify which attributes should be inverted However, a query ls formulated independently of whether there exist inversions or not. Durling execution of a query the system exploits the advantages offered by inversions and maintains the inversions without any burden on the user except unavoidable storage and time overhead $/ 175 /$.

A more comprehensive approach to data independence starts with the development of a flexible data definition and mapping language. Taylor, and with a silghtly madifled motivation, Smith have developed such languages ar a data model very close to the DBTG model/179, 
169/. As pointed out earlier, SIMS has also such a language, which enables it to operate on given data without converting these data as a whole /194/. The importance of the possibility to access data by means of a rescription and without converting the data as a whole is illustrated by the existence of data collections, which to convert to a standard form is more expensive than rewriting all the application programs operating on these date $/ 166 /$.

The evaluation of a data definition and mapping language in a full size data base management system is a very complex task. This fact has probably given impetus to experiments with such languages in the area of data translation, which has also a justification in its own right. Data translation is the conversion of data, which have been created and processed in one system, to a data organization which allows processing in another system. The orientation of these projects combines practical orientation with experimental evaluation of the power of mapping languages, while the projects still remaln small enough to be conducted in less than a large group.

Ramirez et al. have built a compiler, which generates conversion programs from data descriptions /142/. This work makes use of the mentioned data definition and mapping language developed by D. P. Smith. Similarly, Taylor's language is used in another major activity at the University of Michigan / Merten, Fry, 126/. This workis continuing with increased functions being bulit into the currently running prototypes. The underlying data models in both projects are pBrG oriented. The usefulness of $C R M$ as internal form of data during translation has been investigated by Navathe and Merten /133/ with a negative result. Liu and Heller have used contextfree grammars as data descriptions at the record level /108/. Housel, Lum and Shu have developed a Ianguege DEFINE (mapping to a hierarchical structure) for data definition and a language CONVERT (mapping between hierarchical structuresl for translation definition and plan to implement these languages in a prototype $/ 95,165 /$. Again their model of data is that of a graph, which, for the purpose of translation, is decomposed into hierarchles. In a network of computers, such as the ARPA net, data conversion is of particular importance. Su and Lam, and also Schneider and Desautels describe an approach to data translation specifically oriented towards this use $/ 177,153 /$. 


\subsection{Deta Integrity and Recovery in Multi User Systems}

Though the problems, which exist with respect to data integrity and recovery are also present in single user systems, they are enormously increased in a system with many concurrent users. In fact, without multi-user support, traditional means under user responsibility may be adequate for dealing with these problems. In a nulti-user system the system has by necessity to take over some of the responsibility for the solution.

The notion of data ln kegrity is closely connected with the notion of consistency and the schema. A schema may be viewed as a collection of assertions about the data base contents which stay invariant during processing. These assertions are also called consistency rules. such rules may state that information ls in a certain sense complete fror example, whenever something is known about a person, then its mannumber, name, address and bisthdate are known). A more complex rule may require that a person cannot be its own ancestor, or, that the sum of different expenses in a department may not exceed the budget allocated to the depastment. A data base supports data integrity to the extent in which it allows a iser to specify consistency rules, which are subsequently enforced by the system.

A straightforward approach to specifying such rules could consist of the following.

1. Provide the use with a general language like predicate calculus or a guery language to specify assertions.

2. Whenever the data base has been modified, the system checks, whether the assertions still hold.

This appoach proposed for exampie $1 \mathrm{n} / 1,78 /$ and recently also in $166 /$ has to be considered with caution. First, it is for a general language undecidable whether the assertions are in themselves consistent. Second, it has to be carefully defined when the consistency of a data base 1 s checked, since a user must in general perform a numer of modifications to a data base before a consistent state ls again transformed into a consistent state. Third, checking of a set of complex consistency rules may require access to a large portion of a data base, which can range from hours for small data bases to several weeks far larger data bases in processing time. 
The flrst problem can be solved only, if the language in which the consistency rules are expressed, is simple enough so that the consism tency of the rules remains decidable. Practical systems, Iike IMs, certalniy satisfy this criterion.

The second problem has been recognized and has lead to the introduction of the notion of a transaction /65, 66/. A transection is a sequence of transtormations of the data base by one user, which are supposed to transform a consistent state into a consistent state. Beelnning and end of a transaction are under user control. Now consistency checking can take place whenever a transaction is complete.

The third problem is in some way connected to the first one. Given a consistency rule, the system must be capable of determing, how costly l. checking during data base transformations will be. The variation of costs of checking a consistency rule may be 1 llustrated with an example: Given a father relation, a consistency rule may state that the subgraph containing only edges labeled with father is cycle free. Checking this rule requires an algorithm thet is in execution time proportional to $n * 3$, where $n$ is the number of objects participating in the father relation. If the stored information contains in addition for every person the birthdate, the rule that the birthdate of the father precedes the birthdate of the son, serves the same purpose as the previous cycle rule. This rule can, however, easily and efficiently be verfied for every data base change. In most situations "system enforced integrity" makes only sense, if the time needed for the enforcement is bound by a linear function of the time necessary to perform processing without integrity assurance. A compiled approach like the assurance of integrity constraints by query modification, as proposed by stonebrecker /176/, may help since it allows comparative analysis of the queries with and without constraints. of course, such an analysis does not have to be at the source level.

The problem of integrity is lncreased with concurrent access by more than one user. The system has, in addition, to ensure that the users do not interfere with each other during update operations. To this end the system must provide a facility which gives a user exclusive access to a part of the data base for a limited time. Basic mechanIsms for granting exclusive access to a user are well known from operating systems under the names of locking or semaphores. 
165/. A camplication of locking in data base systems, also explained in $/ 65 /$, is the need to lack objects, which may not yet exist, from being created $80 \%$. There are an infinite number of objects which may potentially be created (though the set of created objects is always finitel. Such locks may be described by predicates with an infinite extension. Performance requirements dictate that it can be decided for two such predicates whether they overlap. This imposes restrictions on the formulation of predicates to be handied by the system /65/.

Locking has as consequence the danger of deadlocks. As in operating systems there are essentially two ways to deal with deadlocks. The first, proposed for example by Everest $/ 67 /$ is preclaiming. With preclaiming of resources the system can schedule the user's transactions such that no deadlock appears. The second solution is preemption, i.e. taking away resources from one process to give the resources to the other process. The preempted process has then to be positioned back to a state in which it did not hold the resources. This is possible with the help of Journals and checkpoint files, i.e. data sets which record the internal state of a process during its execution /83/. This method is discussed by Chamberlin et al/29/. It should be noted that these lies are required in most systens for recovery purpose.

Recovery is necessary whenever it is impossible for a transaction to terminate normally. The cause for this may be a deadlock, a loelcal error in the user's program la zerodivide exception or a consistency check falure, for example), a hardware fallure, or the failure of a transaction which has directly or indirectly (via the data base) deLivered input to the transection. The first objective of recovery is the isolation of a failure, such that an error does not propagate in the data base. A second objective is to restart all transactions which have been affected by a fallure without being the cause such that they continue execution as if no fallure had appeared. This is to a large extent possible. Recavery elgorithms have been described by Genton $/ 83 /$, Davies /50/, Bjork /15/, Edelberg /62/ and Sayani /148/. The basis for much of this work has been laid by recovery in operating systems such as Motrics $/ 81 /$.

All solutions to the integrity and recovery problems must of course avoid placing an unnecessary burden on the user. The most that should be expected from an application programer is to inform the system of the beginning and the end of transactions. The interactive problem 
solver should not be required to know about transactions. He should, as far as the query language is concerned, be able to act as if he were the only user of the system.

As with data independence, the problems discussed in this secton are at the beginning to be understood. There is certainly significant room for lmprovement over proposed and existing solutions, in particular, In providing the functions with improved performance.

\section{STORAGE STRUCTURES AND SEARCH ALGORITHMS}

Data independence as discussed in the preceding section derives its value (a) from the existence of storage organization techniques which reduce the sometimes enormous search time required otherwise and (b) from the existence of algorithms which allow to utilize the storage structures without binding the programs to these structures. The next two subsections are devoted to these two topics.

\subsection{Storage Structures}

One of the frequently employed techniques is the acceleration of a search with one parameter with the help of an inverted file. If the inverted file is repeatediy inverted we obtain an hierarchical index organtzation described by Bayer and McCreight and known as iB-Tree". B-Trees allow a logarithmic search time for retrieval, update and insert /9/. Lum introduced multi-attribute indexes which allow quicker answers to queries of higher complexity/112/. Finkel and Bentley describe an extension of binary trees to quad trees supporting logarithmic searches with two parameters /77/. Haerder describes methods of address list compressions ('bit 11 list $^{\prime}$ to reduce the storage costs of indices in certain cases $/ 30 /$.

Another method of reducing search time ls hashing Hashing has been extensively studied in connection with its application to data management $/ 113,115 /$. Ghosh and Lum have recently shown that under their assumptions, hashing by division is in general best / $85 /$.

of course, there are a number of additional, essentially basic techniques applied to data organization such as links between or the splitting of records. These methods may be combined in various modifi- 
cations. Storage structures have been extensively studied in the past and are well described in textbooks and surveys $/ 54,99,100,118$, $120,135,160 \%$. The problem remains to offer this richness of structures to programs without binding the programs to specific structures, 1.e. to offer the structures with data independence. In the case in Which the program does not know the internal organization, it is the system s responsibility to utilize the storage structures optimally. Attempts to solve this problem are discussed in the next subsection.

\subsection{The Reduction Problem}

Reduction is the pxoblem of reducing external accesses to internal access, where the relationship between internal and external representations are given by mappings of these forms to a conceptual form (2ig. 1). Reduction is something like an "optimization" with the primary objectlve to peduce the number of accesses to secondary storage during execution of a query or an application program. The term "optimization" shoula not evoke unrealistic expectations; the problem is too complex and is loaded with similar problems as optimization in a compiler.

Variations in the objectives of optimization are connected with the handing of Internediate expressions over data sets. Consider, for example, the expression

$$
(\mathrm{A} \text { op } 1 \text { B) op? }(\mathrm{C} \text { op? D) }
$$

where $A, B, C, D$ are large felations and opl to op3 are operators in the relational algebre. A straightiorward evaluation might construct two intermediate relations $A B=A$ op $1 B$, and $C D=C$ op 3 and then evaluate $A B$ op2 $C D$. Such an algorithm requires in additon to enormous amounts of secondary storage accesses also an enormous amount of auxiliary storage, which may by far exceed the storage occupied by the underlying relations $A, B$, $C$, and $D$. On the other hand, there are drastic improvements in the evaluation of some queries if during their evaluation at least some temporary inversions can be bullt. Most of the research $\ln$ this rea is primarily oriented towards the interactive use of a data base of modest size and consequently assumes that auxiliary data sets (i.e. indices) can be built temporarily for one query execution. 
One of the earliest comprehensive investlgations into this problem is due to Palermo /140/. Palermo clalms that for the investigated type of queries no tuple has to be accessed more than once. This is achieved by bulding indices and restricting the domains of variables in calculus expressions and applying a "least growth principle" for the sequence of operations. A reduction algorithm applicable to the DIAM system is described by Astrahan, Ghosh and Senko /5, 84/. Greenfeld and Rothnie look at the problem of handiling quantification ln calculus expressions efficiently /89, 147/. Another implemented version of a reduction algorithm is described by Astrahan and Chamberlin /6/. Their problem consists of primaxily taking advantage of inversions, but their algorithm involves also the construction of intermediary 11 ists (indexes) by merging of inversions.

A paper related to the reduction problem is due to wong/Chiang. They assume that each query is a boolean expression over elementary queries. In this case the data base can be organized according to the elementary queries and reduction becomes essentially the problem of putting a boolian expression into some standard form $/ 195 /$.

CPU usage has not received much attention, perhaps under the assumption that cPU time is not the bottleneck in the system. This assumption is, however, not always valid. To reduce CPU time, less dynamic and less interpretive search stategies are required, which can be compiled into a CPU efflcient search module or access module per application. As mentioned earlier, the compiler approach has been taken or proposed by several researchers primarily, however, for other reasons than eficiency/Mehl, Fernandez, Conway, also Taylor in 125, 75, 44 and $180 \%$.

It should be clear that the reduction problem is very complex. Fvery algorithm described above has to make a number of assumptions with respect to system structure, which are not generally valid. This has to be so, as long as there is no generally respected data base architecture. Questions, which potentially deserve more attention in future research are the recognition of constraints in storage requirements and CPU time in addition to "minimizing" secondary storage accesses. 
learn about existing systems by analyzing their behaviour and to develop simple probabilistic models for the components of a data base management system. Such models may help to predict the influence of changes in a system or system design. Thus the designer of a data base management system and even more, the data base administrator should have primary interest in these research activities.

The need for modeling of data management system and data base systems has been recognized early by senko and his colleagues and lead to the development of an analysis tool called FOREM and a follow-on tool called PHASE II $/ 154,138 /$. Haerder has recently performed a comparative enalysis of curpent indexing techniques using these tools $/ 91 /$. FOREM and PHASE II are useful to evaluate storage organizations, but limited with respect to overall data base system slmulation. Nakamura et al. report about a data base simulation model which they have constructed with the help of a conventional simulation package/132/. Their model is a fairly detailed, event driven simulator of the processes in a data base manegement system. These processes are so complex that questions of simulation performance may become critical. A possible way out may be the development of comprehensive data base system simulating tools. A step in this direction is proposed by Rei$\operatorname{ter} / 144 /$.

Data base systems have also been objects of analytical modeling activities though they are clearly too complex to be analytically treatable as a wole. Analytical studies restrict themselves therefore to well defined parts of the system. FORPM is an example of a deterministic analytical tool for the analysis of starage structures. The methods proposed by Cardenas in $122 ;$, Yao in /196/ and Wedekind in /193/ are also essentially deterministic.

To mention is also the analytically tractable queueine model of the DL/I component of rus developed by Lavenberg and shedier /103/. Though they allow for "rather general" distributions, their model is at a gross level. For example, lt does not explicitly represent the physical storage organization and total i/o is represented by a single server queue. Extensions of the model are, however, likely to make simulation necessary.

Perhaps the most frequently investigated question is the selection of indices to a flat file. Authors, who have contributed to research on this problem under varying assumptions are lum and Ling/114/, Palermo 
/139/, stonebraker /174/, King /98/, Cardenas /23/, Schkolnick /150/, Yue and Wong $/ 197 /$ and Farley and stewart $/ 71 /$. Shnelderman has investigated the question of index size at different levels /164/.

Data may be allocated to or destributed over a variety of categories: first, data have to be allocated within a storage hierarchy in an attempt to balance between costs and access time, second, data have to be assigned to physical devices to minimize contention given their position in the hierarchy, third, in case of a network like the ARPA net), data have to be assigned to nodes in the network to improve accessibility and reduce line costs. Lum et al. as well as Buzen and Chen have considered the problem of allocating data within a storage hierarchy, given statistical information on the usage of the data sets /116, 21/. Lum et al. specify a total cost function to an allocation and an algorithm which finds the allocation to a minimal cost. Buzen and Chen's model takes in addition queveing effects at the hierarchy levels into consideration. Their algorithm's target is to minimize response time under given storage constraints.

The second problem, minimizlng disk arm contention by suitably distributing data sets over a number of disk drives given their usage statistics, has been considered by Chandra and Fong and recently also by Easton and Wong $131,60 /$. There is no best algorithmic solution, but heuristic approaches are given and some bounds for the optimality are derived.

Cesey and Chang have considered the third problem of allocating data within a simplified network of computers to reduce line costs/26, 27 , 32/. Chang has extended Casey's linear cost functions to a more general function. Both specify algorithms, which attempt to minimize line $\operatorname{costs.}$

With the analysis work reported so far, at least one question remains open: what are the characteristic input data? or, with other words, how is the workload of a data base system statistically characterized? Nakamura et al. In their simulation raise the further question of the validity of their model. Answers to such questions can only be found by actually observing operational systems and collecting statistics. Rodriguez and Hildebrand describe how relevant data ranging from a log of the user's messages, over a trace of the application program calls (to the data base system) to a trace of physical disk address references can be collected in operational systems /145/. Lewis and Shedler 
derive from such observations that the interarrival times between transactions can be satisfactorily modeled by a non-stationary poisson process (i.e. a Poisson process with a time dependent rate) /107/*

In a semi-emplrical approach, Ghosh and Tuel, and also Easton, determine the parmeters of a theoretically established model to make the model fit to empirical data $/ 86,61 /$. Ghosh and Tuel model certaln interactions in a data base system by linear relationships and determine the coefilcients by comparison with measurements, which are also used to valldate the mode1. Easton has proposed to use an extension of the independent reference model for the sequence of references of application programs to blocks on secondary storage and again has validated this model by comparison with the behaviour af a large data base system.

It is clear that the objective to obtain representative models and validated workload characterizations has not yet been convineinely met. The reasons for this are connected with the current state of the art of data base research in general, which will be summarized in the next section. However, it is also clear that research on modeling and analysis of data base systems as described in this section has made significant progress, and that its continuation is extremely important from a practical point of view.

\section{SUMMARY AND CONCLUSIONS}

Before we try to summarlze the research activities of the past, at least two major factors have to be considered:

Data base systems a re in thel objectives of a complexity that is in our opinion by far greater than the complexity of programming language implementations or operating systems. Consider alone the goals of data integrity and data independence. In conventional systems, the integrity remains the responsibility of the user, in a data base system the system has to take over a large part of this responsibility. In a conventional system a user"s program may be device independent due to implenentation of equivalent storage structures on different devices. The goal in a data base system requires that the user's program ls not only independent of different storage on the same (or another) device, but also that the system takes advantage of current structures during 
access where restructuring is under control of the user in his data base administrator role.

The area of data base systems research is new. Major activities started only a few years ago. Understanding the real problems takes a large amount of time; demonstrating the viability of a solution requires expensive prototype lmplementation efforts. Before such large implementations are performed, the risk of fallure has to be reduced by prior assessment. This Justifies that a fair amount of research was spent in clarification. For example, it is sometimes held against the researchers that they are engaged in a "religious war" around data models. The question, which data model is taken, is certainiy lmportant and of a similar nature as the question, which programming language should be supported. However, data base researchers are now discussing the problem of different models with a changed attitude: it is not so much the question of selecting between two models but more the question of how one model can be represented on top of the other.

A number of promising activities have been started and will continue, which design and evaluate the man-machine interface for the interactive problem solver. In another branch of research, investigations into the system aspects have reached a level that prototype efforts are justified and now under way.

Data translation, driven by data description and mapping languages, continues to be investigated with increased power of the languages. With respect to storage structures there is already more available than can be intelligently handled by data base management systems. Research probably has to put mare emphasis on how these structures can be efficlently utilized.

Modeling systems in a way that significant help results for the data base administrator is in its beginning. It will take some time, before the research which has already been conducted and has to be continued is combined into a useful set of tools for the system designer or administrator.

Comparing the obtained results with industry activities we may see first a difference of emphasis. Systems like Iys are primarily designed for and employed by parametric users while research systems are primarily designed for the interactive problem solver. With the current state of art, it is likely that research changes priority some- 
what in favour of the parametric user. The modeling and analysis work described in section 6 is already now primarily oriented towards running, productive systems.

\section{Conclusions}

With the wealth of pesearch existing, it becomes meaningful to ask: what are among all these results the major achievements? Are there any trends recognizable ith respect to a change of research direction? What are currently the major problems? Fhile we are trying to answer these questions, we are well aware that the reader may wholeheartedly disagree.

\section{Major results}

1. Model Development for Data Independence

one of the primary achievements of past research is the adreement on a type of data base system structure, which is shown in flg. 1. In particular, this means that we have to deal with at least three levels of information (conceptual, internal, externall that users assume different roles (parametric, problem solving, application programming, and data base administrating) and finally that the user in his data base administrator function has control over storage structures to tune the performance of his installation.

2. Multiple Records at a Time Logic

Due to the orientation of research to the interactive problem solver, nigh level multiple recort at a time logic bas been developed exceeding in power and flexibility the feacures offered in many comercially available systems. In particular the notions of views and predicate locks are of simila importance to the parametric use of data bases as to the problem solving use.

\section{Storage structures}

Storage structures like the g-trees or to say it more generally "what can be cound in Knuth vol. 3 , chapter 6" or other textbooks represent important results and are basic to futore sesearoh activities. 


\section{Recognizable Trends}

1. Data Model Coexistence

After years of controversies, it is increasingly realized that different models have their justification even within the same system. The coexistence of different models in one system is called the superimposition problem and likely to find more attention in the future.

2. Integration of the DAMS into the os

Past research has made apparent that many of the problems in the area of scheduling, resource management and recovery, i.e. classic operating system functions, cannot be solved outside the data base management system. Increased experience in this area has already lead to systems, which in much respect contain operating system functions. It can be expected that further research makes the need of integrated solutions to operating, time sharing and data base management systems even more apparent.

\section{Data Dictionary/Directory}

With the current merge of operating systen and data base management system arises a large number of places where descriptive information about data and programs is stored in the system. A trand is recognizable to combine these different types of descriptions into a central data dictionary, therehy ensuring more consistency among the descriptive data and generally offering a simpler interface to the user for maintaining the descriptive information.

\section{Major problems}

\section{Performance}

Performance in the sense of throughput and transaction rate constitutes currently the major problem. It is generally felt that current systems to not offer the level of achievable performance, though this can only be proved by better performing alternatives. In particular, that CPU time may constitute a bottleneck has not been recognized in the past and research is necessary in this area. 
2. Integrity, Data Independence, Recovery

It is necessary to provide more possiblities of specifylng system enforceble integrity rules and data representations, which can be handled by the system with efficiency. The emphasls here is on more functions and efflclency to provide these functions ignoring efficiency is trivial) so that the users installation as a whole has benefit. Similarly techniques which allow rapid recovery from fallures are extremeIy desirable and lacking.

\section{Concurrency}

The problems of concurrency (deadlock prevention, scheduling) again in comnection with efticiency, have not been solved in a setisfactory way. These problems increase in multiprocessing systems and with data bases, which are distributed on a network of computers.

\section{Design Tools}

In todays systems, and even nore so in future systems, the user has to make a number of decisions like: how to model the conceptual information, or how to select hardware and physical representation. With the current state of the art, he is not given much information, which helps in maklng these decislons. Some of the research reported in section 6 is certainly relevant for the development of such tools.

\section{Deta Reopganlzation}

In a dynamic system with acdition, deletion and update of stored information it is inevitable to physically reorganize the data from time to time. The reason is a type of physical disorder like storage fragmentation, which does not affect the logical order, but degrades performance and storage utilization. To reestablish physical order, it is, in general, necessary to dump and reload significant parts of the data base as a whole, which is therfore not avallable during this process for normal use. For large data bases, which are used around the clock, the interruption may become too long to be talerable. (The time range is from hours to weeks for a reoreanization). A solution to the reorganization problem is necessary which avoids interruption. 


\section{Acknowledgement}

The authors are grateful to their collegues at the IBM Heidelberg Scientific Center, to members of the IBM Research staff at Yorktown Heights and San Jose and to representatives from Universities in Europe and North America for many helpful discussions. Specificaliy they are grateful to E. F. Codd and M. E. Senko for a critical review of a preversion of this report.

\section{BIBLTOGRAPHY}

The subgequent list of references contains the basis for this status report. It is hoped that it is also of value as a reference to recent research results. Where present, the annotations are intended to help the reader in selecting literature. They should not be considered as critical reviews, which can be found elsewhere. Subsection I contains alphebetically ordered lists of cross references in numbers referring to entries in subsection II, which is a partially annotated list of references, ordered according to first author.

\subsection{Cross Reterences}

Data Definition Languages

$\begin{array}{lllllll}35 & 37 & 82 & 95 & 142 & 152 & 166 \\ 169 & 179 & 194 & & & & \end{array}$

Data Independence

$\begin{array}{lllllll}47 & 48 & 55 & 82 & 125 & 152 & 175 \\ 180 & 181 & 182 & 194 & & & \end{array}$

Data Integrity

$\begin{array}{lllllll}1 & 29 & 30 & 45 & 65 & 66 & 78 \\ 129 & 163 & 176 & & & & \end{array}$

Data Manipulation Languages

$\begin{array}{lllllll}1 & 3 & 6 & 13 & 16 & 17 & 18\end{array}$




$\begin{array}{lllllll}19 & 20 & 25 & 28 & 35 & 36 & 40 \\ 42 & 46 & 59 & 68 & 69 & 70 & 72 \\ 73 & 74 & 79 & 87 & 93 & 101 & 102 \\ 105 & 106 & 109 & 110 & 119 & 123 & 128 \\ 131 & 136 & 141 & 143 & 147 & 149 & 155 \\ 158 & 173 & 183 & 184 & 185 & 194 & 198\end{array}$

Data Model Bquivalence

$\begin{array}{lllll}77 & 82 & 122 & 134 & 167\end{array}$

Data Models

$\begin{array}{lllllll}1 & 2 & 4 & 7 & 8 & 14 & 20 \\ 34 & 35 & 38 & 39 & 41 & 43 & 52 \\ 56 & 57 & 58 & 63 & 68 & 69 & 70 \\ 79 & 121 & 124 & 133 & 151 & 155 & 157 \\ 178 & 190 & & & & & \end{array}$

Data Securley

$\begin{array}{lllll}30 & 44 & 75 & 94 & 171\end{array}$

Data Translation

$\begin{array}{lllllll}95 & 108 & 126 & 142 & 153 & 165 & 177\end{array}$

Modelling and Analysis

- General

$\begin{array}{lllllll}24 & 61 & 85 & 86 & 91 & 103 & 107\end{array}$

$\begin{array}{lllllll}113 & 115 & 117 & 127 & 132 & 137 & 144\end{array}$

$161 \quad 188 \quad 193 \quad 196$

- Tools

$\begin{array}{llllll}12 & 22 & 138 & 145 & 154 & 170\end{array}$

- Optimization Alforithms

$\begin{array}{lllllll}21 & 23 & 26 & 27 & 31 & 32 & 33\end{array}$ 
$\begin{array}{lllllll}60 & 71 & 88 & 97 & 98 & 114 & 116\end{array}$

$\begin{array}{llllll}139 & 150 & 162 & 164 & 174 & 197\end{array}$

Privecy

$\begin{array}{llll}76 & 94 & 171 & 187\end{array}$

Recovery

$\begin{array}{llllll}15 & 50 & 62 & 81 & 83 & 148\end{array}$

Resource Allocation and Scheduling

$29 \quad 30 \quad 65 \quad 67$

Search Algorlthms

$\begin{array}{lllllll}5 & 6 & 84 & 92 & 140 & 147 & 195\end{array}$

Storage Structures

$\begin{array}{lllllll}9 & 10 & 11 & 51 & 77 & 80 & \text { n0 } \\ 96 & 111 & 112 & 130 & 146 & 155 & 182 \\ 186 & 189 & & & & & \end{array}$

Surveys and Textbooks

$\begin{array}{lllllll}8 & 49 & 54 & 64 & 99 & 100 & 104 \\ 118 & 120 & 135 & 156 & 160 & 172 & 191 \\ 192 & & & & & & \end{array}$




\subsection{References}

1. Ahrlal, I.R. Data Semantics. Data Base Management, Proce of IFIP Work. Cont. Cargese, Corsica April 1974. North Holland, Amsterdam 1974 .

The paper is mathematical and philosophical with a scope exceeding the data base manaement area. It describes and advocates a data model with binary relations between entities.

2. ANST/X3/SPARC. Interin Report: Study Commitee on Data Base Management Systems. ACM SrGMoD Newsletter 1975.

3. Ash, W. L, and Sibley. TRAMP: An Interpretive Associative Processor with Deductive Capabilities. 1968 ACM Nat1. Conference, $144-156(1968)$.

TRAMP is the implementation of a binary relational model in a question answering system. It accepts definitions of celations in terms of other relations le.g. the grandfather as a function of father and nother) which leads to deductive capabilities.

4. Ashany: $R$. Concepts of Data Manipulation. The Connection Matrix Method. IBM System Development Division, Poughkeepsie. T.R. 00.2200 une 1971

Information is represented as a binary matrix, where the rows represent entities, the columns represent attributes, and a 1 in a position indicates that the attribute is true with respect to the entity, otherwise false. Sparse matrix techniques have to be applied to reduce storage requirements.

5. Astrahan, H. H, and Gosh, S. P. A Search Path Selection AlgorIthm for the Data Independent Accessing Model (DIAM). Proc. 1974 ACA SIGFIDET Workshop, ACM, New Yark, 1974.

A heuristic alforithm is described which constructs a DIAM access path to a given query in RIL (Fehder).

6. Astrahang $M . M$. and Chamberlin, D. D. Implementation of a Structured English Query Language. CACM 18, $580-588$ (1975). Describes essentially the SEQUEL interpreter and the reduction algorithn enployed by 1 to make use of secondary indexes for "minimization" of data accessing operations.

7. Bachmann. C. W. The progumer as Navigator. CACM 16, $653-658$ 
$(1973)$

C. W. Bachmann's famous 1973 ACM Turing Award Lecture.

8. Bachmann, C. W. Trends in Data Base Management. AFIPS NCC 1875 Proc. vol. 44,569-576(1975).

Trends are:

1. The evolution of a tripartite data description lconceptual, internal, externall as used by ANSI/X3/SPARC.

2. The current debate data structured model (graph, network) vs relational model contributes to the understanding of the nature of data. 3. The introduction of new hardware to support data base algorithms.

9. Bayer, R., and McCreight, E. Organization and Maintenance of Large Ordered Indexes. Acta Informatica $1,173-189$ (1972). The described hierarchical index organization (B-tree) has become a standard storage structure. Logarithmic search and efficient insert, delete are characteristics of the method.

10. Bayer, R. Symmetric Binary B-trees, Data Structure and Maintenance Algorithris. Acta Informatica 1, 290-306 (1972). Symmetric Binary B-trees are a modification of the storage structure described by Bayer and Mccreight.

11. Bayer, R. Storage Characteristics and Methods for Searching and Addressing. Information Processing $74,440-444$, North Holland, Amsterdam, 1974 .

The paper contains a discussion of hashing and B-trees in random access, pseudo random access $(1, e$. Indexed sequentiall and virtual memories.

12. Bennet, B. $\mathrm{T}$, and Krusikal, V. I. Stack Processing for Data Bage Systems. To appear in IBM J.of Res. and Dev. (1975).

Traditional stack processing algorithms are inefticient for large average stack distances as they appear in the case of a large number of distinct pages. The authors describe a new algorithm to handle this situation with drastically improved efficiency.

13. Bergen, M., Erbe, R., Pistor, P., Schauer, D., and Walch, G. An Environment for the Interactive Evaluation of Scientific Data and its Application in Computer Aided Design. Proc. Workshop on 
data bases fox interactive deslgn W. M. Cleemput and I. G. Lindexs, editorsl, Waterloo, Canada, September 15-16, 1975, available from ACM. See also Schauer /149/.

14. Biller, Hq and Neuhold, E. J. Formal View on Schema-Subschema Correspondence. Information Processing 74 , Proc. of IFIP Congress, North Holland, Amsterdam, 1974.

15. Bjork, L. A. Recovery Scenario for a DB/DC System. 1973 ACM National Conf. Proc. 142-146(1973).

This paper is the second of two papers describing a recovery concept in a data base system. See C. T. Davies for the first or the two papers.

16. Bjorner, D.: Coda, E. F, Decker, K. L., Traiger, I. L. The Gamma-Zero n-ary Relational Data Base Interface: Speciflacations of Objects and Operations. IBM Research Report RJ 1200, 1973.

A detailed description of a low level query language accessing a relational data base.

17. Bobrow, $R$ al An Experimental Data Management System. In Data Base Sytems $(R$. Rustin editorl, Prentice-Hall, Englewood Cliffs, 1972 .

The paper describes an experimental system implemented in LISP. It contains a brief but excelient discussion of the EDMs (hierarchy or network) approach vs. Codd's relational approach*

18. Boyce, $R$. F. : Chamberlin, D. D., King, W. F., and Hammer, M. M. Specifying Queries as Relational Expressions: SQUARE. Data Base Maragement, Proc. of IFrP Work. Conf. Cargese, Corsica, April 1974, North Holland, Amsterdam, 1974 .

SQUARE is a syntatically terse, set oriented, high level query language based on the so-called "concept of mapping". See also Chamberlin/Boyce for "SEQUEL".

19. Bracchi, G., Fedeli, A. and Paolini, P. A Relational Data Base Management System. Laboratorio di Calcolatori, Instituto di Elettrotecnica, politechnica di. Milano, Internal Report No. $72-5$, 1972 .

MORIS is a Codd relational systen with a calculus oriented manipulation langiage. The users view (external schema) may include hierarchical structures (i.e. unnormalized data). 
20. Bracchi, G., Fedeli, A, and Paolini, P. A Multilevel Relational Model for Data Base Management Systems. In Data Base Management, Proc. of IFIP Work. Conf., Cargese, Corsica, April 1974, North Holland, Amsterdam, 1974.

Advocates the binary relational model (graph model) for the conceptual schema and many models for the external schema (hierarchical, codd relational, etc.) as well as internal schema.

21. Buzen, J. P., and Chen, P. P.-S. Optimal Load Balancing in Memory Hierarchies. Information Processing 74, 271-275. North Holland, Amsterdam, 1974 .

A queuing model for the access to data sets in a memory hierarchy is used to analyze the allocation of data sets. The paper offers a generalization of Chen's results.

22. Cardenas, A. F. Evaluation and Selection of File organization a Model and system. CACM 16, 540-548, 1973 .

A program is described, which may be used to estimate total storage costs and average access $t$ ime given the data organization and device related specifications.

23. Cardenas, A. F. Analysis and Performance of Inverted Data Base Structures. CACM 18, 253-263, 1975.

see also King, Farley/stewart, Schkolnick and Yue/Wong for recent treatments of this subject.

24. Cardenes, A. F., and Sagamang, $J$. P. Modeling and Analysis of Data Base Organization: The Doubly Chained Tree structure. Inform. Systems $1,57-67,1975$.

25. Carison, E. P*, Bennet, J. L., Giddings, G. M*, and Mantey, P. E. The Design and Evaluation of an Interactive Analysis and Display System. Information Processing 74, 1055-1061, North Holland, Amsterdam, 1974 .

GADS is an interactive graphics systen for data related to eographic locations and intended as a tool to be used by non-programmers. It provides a data extraction technique for accessing data stored in a variety of files. The paper discussesexperience gained with GADS and the requirements, which must be met by a system of this kind. 
26. Casey, $R$. G. Allocetions of Copies of a File in an Intormation Network. AFIPS SJCC 1972 Proc, vol. 40,617-225, 1972.

The author gives an exact and a heuristic solution to the problem of allocating data sets within a network of computers, given the costs of storing at and transmission between nodes.

27. Casey, R. G. Design of Tree Networks for Distributed Data. AFIPS NCC 1973 Proc. vol. $42,251-257,1973$.

28. Chamberlin, D. D. and Boyce, R. F. SEQUEL - a Structured EngIish Query Language. ACM STGFIDET Workshop 1974, ACM, New York, 1974 .

SEQUEL is a language with semantics very similar to those of SQUARE, however, with a syntax closer to natural English. See Boyce Chamberlin for SQUARE.

29. ChamberIin, D. D., Bayce, R. F. and Traiger, I. L. A Deadicck Free Scheme fox Resource Locking in a Data Base System. Information Processing 74, 340 - 343. North Holland, Amsterdam, 1974. The authors propose to use deadlock-detection and backout of processes in case of deadlocks. Their algorithm ayoids indefinite delays of a process.

30. Chamberlia, D. D., Gray, J. N., Traiger, I. L. Views, Authorization and Locking in a Relational Data Base System. 1975 AFIPS NCC Proc. vol. $44,425-430,1975$.

A vier is a virtual relation derived form other relations via the query language SEQUEL. The problem of updating views is discussed. Views can be used for authorization. Locks temporarily restrict the access to a view for the exclusive use of one user.

31. Chandra, A. $K$, and Fong, C. K. Worst Case Analysis of a Placement algow thm related to storage Allocation. To appear in SIAM Journal on Computing.

The authors specify a heuristic algorithm to allocate data sets to disk drives such that the probablity of simultaneous access or one disk drive is minimized. The worst case performance of the algorithm is analyzed. See also Easton/Wong.

32. Chang, S.K. Data Base Decomposition in a Hierarchic Computer System. ACM SIGMOD 1975 Int. Conf. on lgmt. of Data, San Jose, 
1975.

The author has extended Casey's results by allowing a non-linear cost function.

33. Chen, P. S. Optimal File Allocation in Multilevel Storage System. 1973 AEIPS NCC Proc. vol. $42,277-282,1973$.

A treatment of the hierarchy allocation problem taking queuing effects into considerations. See also Buzen/Chen.

34. CODASYL Development Comittee. Language Structure Group. An Information Algebra. CACM 5, $190-204,1962$.

An "oldtimer" and source for many ldeas. Contains, for example, the definition of an entity or the idea that files may be interpreted as sets of n-tuples on which then jolns, union and intersection can be performed.

35. CODASYL Programming Language Committee. DBTG-Report. 1971. Avaliable from ACM.

The original DBTG proposal.

36. CODAsYl Programing Language Commitee. DBLTg proposal, February 1973.

Contains the COBOL data manipulation and surschema data definition language. The languages are essentially those of ref. 35.

37. CODASYl Data description Language Committee. Data Description Language. Journal of Development, June 1973. Essentially the same data definition language as in 35 .

38. CODASYL Systems Committee. Feature Analysis of Generalized Data Base Management Systems. Technical Report, May 1971. Avallable from $\mathrm{ACM}$.

Primarily compares commercially avallable systems, contains also a network data model.

39. Codd, E. F. A Relational Model of Data for Large Shared Data Banks. CACM 13, 377-387, 1970 .

The paper in which Codd introduced the (codd) relational model of data.

40. Codd, E. F. A Data Base Sublanguage Founded on the Relational 
Calculus. 1971. ACM SIGFIDET Workshop, ACM, New York, 1971.

41. Codd, E. F. Further Normalization of the Data Base Relational Model, and Relational Completeness of Data Base Sublanguages. In Data Base Systems (R. Rustin editor). Prentice-Hall, Englewood C11ffs, 1971 .

42. Codd, E. F. Seven Steps to Rendezvous with the Casual User. In Data Base Management, Proc, of IFIP Work. Conf. Cargese, Corsica, April 1974, North Holland, Amsterdam, 1974.

The description of seven steps to a proposed natural language question answering system. The steps are: simple data model, high level internal logic, clarification dialogue, query restatement, declarative query, multiple choice interrogetion and a definition capability.

43. Codd, E. F. Recent Investigations in Relational Data Base Systems. Information Processing 74, 1017- 1021, North Holland, Amsterciam, 1974 .

A brief survey of Codd"s relational model including a discussion of normalization and data sublanguage types. The author lists concurxency, performance, superimposition and storage access theory among the topics needing investigation.

44. Conway, R. W. Maxwell, W. L., and Morgan, H. L. On the Implementation of Security Measures in Intormation Systems. CACM 15 , $211-220,1972$.

The main ldea in this paper is to perform checking of security only "once at compile time", an approach which is conscious of the CPU as a resource. The paper contains also a discussion of security systems implemented by 1972 .

45. Conway, R. W., Maxwel1, W. L., and Morgan, H. L. A Technique for File Survelilance. Information Processing 74, $988-992$. North Holland, Ansterdam, 1974.

A technique implemented by the authors in their system ASAP is described. Each file has associated with it a set of function declarations, which are compiled into a file surveillance program. All accesses to the file have to pass through the survelilance program, which can then be used to perform certain automatic functions. 
46. Dana, $C$, and Presser, L. An Inforamtion Structure for Data Base and Device Independent Report Generation. AFIPS FJCC 1972 Proc. vol. $41,1111-1116,1972$.

The paper describes high level elements for the generation and manipulation of reports.

47. Date, $C . J .$, and Hopewell, P. Storage Structure and Physical Data Independence. 1971 ACM SIGFIDET Vorkshop, ACM, New York, 1971 .

48. Date, C. J., and Hopewe11, P. File Definition and Logical Data Independence. 1971 ACM SIGPIDET Workshop, ACM, New York, 1971.

49. Date, C. J. An Introduction to Data Base Systems. Addison-tyesley, Reading, Massachusetts, 1975 .

similar to Wedekind's book, one of the first attempts of a comprehensive introduction to data base systems. Many annotated references.

50. Davies, C. T. Recovery Semantics for a DB/DC System. 1973 ACM Nat1. Conf. Proc., $136-141,1973$.

Together with Bjork's paper an easy to understand introduction to a recovery concept.

51. Dearnley, P. A. Operation of a Model Self organizing Data Management Systea. Comp. Journal 17, 205-210, 1974.

Among others the system observes patterns of usage and restructures the data accordingly. Simulation results are reported.

52. Delobel, C., and Casey, R. G. Decomposition of a Data Base and the Theory of Boolean Switching Functions. IBM J. Res. Develop. 17, $374-386,1973$.

Deals with the problem of decomposition of a flat file with (enormous) redundancy into a set of flat flles having the mintmal cover property, i.e. allowing to derive the same information as the original file without allowlng further decomposition.

53. Di Paola, R. A. The Solvability of the Decision Problem for Classes of Proper formulas and Related Results. Rand Corp., Santa Monica, Calif. Technical Report R-803-PR, August 1971. The paper deals with the solvability of the decision problem of 
a class of questions to be processed by Rands Relational Data File. See Levien/Maron.

54. Dimperio, M. E. Data structures and their Representation in storage. Annual Review in Automatic Programming, vol. 5, Pergamon Press, 1969 .

55. Dittmann, $E$. L Rlassifizierung von Datenunabhaengigkelt fuer den System-Entwurf. Technische Hochschule Darmstadt. Berichte der Informatik- Forschungsgruppen DV75-1

56. Doerscheidt, A. Das Konzept des objektbeschreibungsbaumes als Grundstruktur eines graphenorientierten Datenbankmodelis. Lecture notes in computer science $26,532-541$, Springer verlag, Berlin, 1975.

Describes a typically graph oriented data model based on LISP 1 deas.

57. Durchholz, R. and Richter, G. Concepts tor Data Base Management Systems. Data Base Management Proc. IfIP Work - Cont. Cargese, Corsica, April 1974. North Holland, Amsterdam, 1974.

Influenced by the data model of the "CoDAsYL Feature Analysis" the authoss discuss a hierarchical data madel and schema.

58. Earley, J. Towards an Understanding of Data structures. CACM $14,617-628,1971$.

Sketches some ldeas related to a theory of data structures similar to the available theory of formal string languages.

59. Earley, I. Relational Level Data structures for Programing Languages. Acta Informatlca 2, $293-309,1973$.

A proposal for the incorporation of relational level data structures into Algol like languages.

60. Easton, M. Ca, and Fong, C. K. The Effect of Capacity Constraints on the Minimal Cost of a partition. JACN, $22,441-$ 449,1975 .

A new algorithm to the problem consldered by Chandra/wong is proposed, which accepts capacity constraints.

61. Eastong M. C. Model for Interactive Data Base Reference string. IBM Research Report RC 5050, Sept. 1974. 
Describes a modification of the independent references model, which describes measured behaviour well. An advantage of the model is its analytical tractabilitly under working set assumptions.

62. Ede1berg, M. Data Base Contamination and Recovery. 1974 ACM SIGFIDET Workshop, ACM, New York, 1974. The paper describes an algorithm, which for a given error and a given set of data transfers ( 1 .e. $\mathrm{log}$ ) determines the error propagation into processes and data blocks. A recovery algorithm is also described, which restores blocks and reruns processes.

63. Ehrich, H. D. Grundlagen einer Theorie der Datenstrukturen. Acta Informatica $4,201-211,1975$.

A graph oriented data model and eraph oriented schemata within the model are investigated from a more mathematical point of view.

64. Engles, R. W. A Tutorial on Data Base Organization. Annual Review in Automatic Programming vol. 7 part 1 , Pergamon Press, 1972 .

65. Eswaran, K. P., Gray, J. N., Lorle, R. A., and Traiger, I. I. On the Notions of Consistency and Predicate Locks in a Data Base System. IBM Research Report RJ 1487 , December 1974.

The paper defines the notion of transaction, consistency within concurrency, and predicate locks and their consequences. A language for predicate specification is proposed, and an algorithm is presented which determines whether two such predicates overlap.

66. Eswaran, K. P., and Chamberlin, D. D. Functional Specifications of a Subsystem for Data Base Integrity. IRM Research Report RJ $1601,1975$.

Contains a classification of consistency rules. Consistency rules are interpreted as routines to be invoked after changes of the data base.

67. Everest, G. C. Concurrent Update Control and Data Base Integrity. Data Base Management, 241 - 270, Proc. IFIP Work. Conf. Cargese, Corsica, April 1974. North Holland, Amsterdam, 1974. Preclaiming of resources to prevent deadiocks is advocated by 
the author.

68. Falkenberg, E., Meyer, B., and Schneider, J. Resultatspezifizierende Handhabung von Datensystemen. Lecture Notes in computer science 1, Springer Verlag, Heldelberg, 1973.

Informal discussion of the "Gegenstandsmodel1", a data mocel, and of a high level manipulation language for it.

69. Falkenberg, E. Time-Handing in Dafa Base Management Systems. University of stuttgart, Institut fuer Informatik, Internal CIS-Report $07 / 74,1974$.

Adds the dimension of time to (for example: A ls employee of $B$ from $T 1$ to $T 2)$ stored relations and extends a data manipulation language to cope with the time dimension.

70. Falkenberg, E. Strukturierung und Darstellung von Information an der Schnittstelle zwischen Datenbankbenutzer und Datenbank-Management-systeme Thesis, UnIversity of stuttgart, 1975.

A detaled description of a data model and a data manipulation language here both are closely related to concepts in natural language. The model is graphoriented though it allows for n-ary relations which can be land graphically arel interpreted as joins of binary relations.

71. Farley, J. H. G., and Stewart, S. A. Query Execution and Index Selection for Relational Data Bases. Technical Report CSRG-53, University of Toronto, March 1975. See also Cardenas for recent investigations into this subject.

72. Fehder. $F$. L. The Representation Independent Language. IBM Research Reports RJ 1121 (1972) and RJ 1251 (1973).

The papers describe RIL, the data manplation languge to the DIAM system.

73. Fehdes, P. L. The Hierarchic Query Language (HQL) part 1. IBM Research Report RJ 1307, Nov. 1973. Describes a query language to operate on rMs like hierarchic data.

74. Feldman, J. A. and Rovner, P. P. An ALGOL based Assaclative Language. CACM 12, $439-449,1969$.

The high level, Algol like programming language LEAP is based on 
binary associations, which are lmplemented using a hash coding technique.

75. Fernandez, E. B., Summers, R. C., and Coleman, C. P. An Author$1 z a t i o n$ Model for a Shared Data Base. ACM SIGMOD 1975 Int1. Conf. on Memt, of Data, San Jose, 1975.

Authorization is governed by predicates over applications and data base contents and enforced primarily at compile time.

76. Fledler, H. Datenschutz und Gesellschaft. Lecture Notes in Computer Science, vol. 26, 1975

A survey of the discussions on privacy.

77. Finke1, R. A., and Bentley, J. L. Quad-trees: a Data Structure for Retrieval on Composite Keys. Acta Informatica 4,1 - 9 , 1974.

A generalization of binary trees for the search on composite keys.

78. Florentin, J. J. Consistency Auditing of Data Bases. Comp. Journal $17,52-58,1974$.

Consistency rules are predicate calculus expressions over the data base contents. Problems of their implementation are discussed.

79. Frank, R. L., and Sibley, E. F. The DBTG Report: An IIlustrative Example. University of Michigan, ISDOS - working paper - 7 . Shows in detail the steps, which have to be made to get a cOBOL application program running in the DBTG approach.

80. Frank, R. L., and Xamaguchi, K. A Method For a Generalized Data Access Method. 1974 AFIPS NCC Proc. vol. 43, 45-52, 1974 . Describes ideas and a keyword oriented language to tailor access methods to the users specifications.

81. Fraser, A. G. Integrity of a Mass Storage Filing System. Comp. Journal $12,1-5,1969$.

Describes the recovery in MULTICs.

82. Frasson, C. A System to Increase Data Independence in an Hierarchical structure. Lecture Notes in Computer Science, vol. 34 (GI 1975), Springer Verlag, HeideIberg, 1975. 
Describes how IMs structures can be accessed independent of their postion in the hierarchy.

83. Genton, A. Recovery Procedures for direct Access Camercial Systems. Comp. Journ. 13, 123-126, 1970.

Descrlbes elementary checkpointing and journaling techniques.

84. Ghosh, S. P. and Senko, M. E. String Path Search Procedures for Data Base Systems. IBM J. Res* Dev. 18, $408-422,1974$. Within DIAM the reduction of queries to access paths in a network is considered. An algorithm is given, which is claimed to yield an access path of minimum "path cardinallty".

85. Ghosh, S. P. and Lum, V. Y. Analysis of Collision when Hashing by Division. Inform* System 1, $15-22,1975$.

It is analytically shown that "hashing by division" is in general best.

86. Ghosh, S. P. and Tuel, W. G. A Design of an Experiment to Model Data Base System Perfromance. IBM Research Report RJ 1482, Dec. 1974.

The authors construct a linearlzed pertormance model and evaluate the model by comparison ith measurements in an IMS system.

87. Goldstein, $R$. Ce, and Strnad, A. J. The MacAims Data Management System. 1979 ACM SIGFIDET Workshop, ACM, Neł York, 1970. MacAims is an early relational system.

88. Gorenstein, S., and Galat, G. Data Base Reorganization for a Storege Hierarchy. IBH Research Report RC 5063, Oct. 1974 .

The problem consictered is that of clustering recorts into blocks (1. e units of transfer) in a way as to minimize the number of transters necessary.

89. Greenfeld, N* R* Quantification in a Relational Data System* 1974 AFIPS NCC Proc. vol. 43, $71-75,1974$.

Discusses optimization techniques for a relational system like LEAP (see Feldman/Rovnerl.

90. Haerder, T. Die Implementierung von Zugriffspfaden durch Bitlisten. Technische Hochschule Darmstadt, Berichte der InformatikForschungsgruppen DV74-2. 
The author proposes bit lists as an index organization and investigates when bit lists are superior to conventional methods of indexing .

91. Haerder, T. Zugriffszeltverhalten bei der Auswahl von Saetzen aus einer Datenbank. Technische Hochschule Darmstadt, Berichte der Informatik-Forschungsgruppen DV74-3.

Analysis of access with the help of simulation. Includes a comparison of storage structures for indexes.

92. Hall, P. A. V. Common Subexpression Identification in General Algebraic Systems. IBM UK Report UKSC0060, Nov. 1974.

93. Held, G. D., Stonebraker, M. R., and Wong, E. INGRES - a Relational Data Base System. 1975 AFIPS NCC Proc. vol. 44, 409416,1975 .

INGRES is a relational data management system with calculus based QUEL as its high level query language. An interesting plan of the authors is to 1 ncorporate access control and integrity assurance via query modification at preprocessing tlme.

94. Hoffmann, L. J. (editorl. Security and Privacy in Computer Systems. Melville Publishing Company, Los Angeles, 1973.

95. House1, B. C., Smith, D. P., Shu, N. C., and Lum, V. Y. DEFINE: A Nonprocedural Data Description Language for Defining Information Easily. Proc. of ACM Pacific, San Francisco, April 1975, ACM, New York, 1975 .

Describes a language DEFINE to map graph structures to a 11 near form, which is then referenced by (and processed according to) a translation specification, written in the language convert. see shu et al.

96. Inglis, J. Iverted Indexes and Multilist Structures. Comp. Journ. $17,59-63,1974$.

Discusses how to use multilist structures in order to maintain inverted files.

97. Karp, R. M., McKellar, A. C., and Mong, C. K. Near-optimal solutions to a 2-dimensional placement problem. IBM Research Report RC 4740, also to appear in SIAM Journal of Computing. The problem considered is the placement of records in a 2-dimen- 
Slonal Storage array, so that the expected distance between two consecutive references is minimized.

98. Fing W. Fo on the selection of Indlces for a File. IBM Research Report RJ 1341, January 1974.

See also Cardenas for recent research in this area.

99. Knuth, D. E. The Art af Computer Programing, vol. 1: Fundamental Algorithms. Addison-Wesley, Reading, Massachusetts, 1968.

100. Knuth, Do E. The Art of Computer Programming, vole 3: Sorting and Searching. Addison-Wesley, Reading, Massachusetts, 1973.

101. Kogon, $R *$ Latermann, D., Lehmann, H., ott, N., and Zoeppritz, M. User Specialty Languages: General Information. IBM Germany, Scientific Center Heidelberg, Technical Report 75.08.007, 1975. An interactive system is introduced designed to a cata manipulation language, which is very close to natural language.

102. Kraegeloh, $\mathrm{K}$. P. and Lockemann, P. C. Retrieval in a set-theoretically Stwcutred Data Base: Concepts and Practical Considerations, Proc. of International Computing symposium $1873,531-$ 539. North Holland, Amsterdam, 1973.

The described system has a natural language like query language, which is translated into a "set theoretic" Intermediate language suitable for interpretation.

103. Lavenberg, S. S. and Shedler, G. S. A Queuing Model of the DI/I Component of IMS. IBM Research Report RJ $1561,1975$.

A simplified, analytically tractable queuing model of the processes during data base access.

104. Lefkovitz: D. File structures for On-Line Systems. Spartan Books, 1969.

105. Levien, $R$. E. and karon, M. E. A Computer System for Inference Execution and Data Retrieval. CACM 10,715-721, 1967.

Introduces the Relational nata File, a system based on binary relations (see also Di Paola).

106. Levit, $G$, Stewart, D. H., and Yormark, B. A Prototype System for Interactive Data Analysis. 1974 AFIPS NCC Proc. vol. 43, 63 
$-69,1974$.

Describes an implemented system for analysis of measurement data relying on standard analytic procedures. It makes heavy use of graphics and statistical methods.

107. Lewis, P. A. W., and Shedler, G. S. Statistical Analysis of Transaction Processing in a Data Base System. IBM Research Report RJ 1629, August 1975 .

Describes the modeling of a transaction stream as a Poisson process with a time varying rate.

108. Liu, S., and Heller, J. A Record Oriented, Grammar Driven Data Translation Model. 1974 ACM SIGFIDET Workshop, ACM, New York, 1974 .

Grammars may be taken as mapplngs of a string to a tree. Iwo grammars mapping different strings to equivalent trees are used as a string to string mapping speciflcation.

109. Lockemann, P. C., and Knutsen, W. D. A Multiprogramming Environment for Onllne Data Acquisition and Analysis. CACM 10, 758764,1967 .

An earlier approach to the problem of measurement data. Prefabricated programs may be assembled communicating via data sets and parameters.

110. Lorie, R. A., and Symonds, A. J. A Schema for Describing a Relational Data Base. Proc. 1970 ACM SIGFIDET Workshop, ACM, New York, 1970 .

Describes RAM - a data base management system based on binary relations (in some sense like LEAP of Feldman/Rovner).

111. Lorie, R. A. XRM - an Extended (n-ary) Relational Memory. IBM Scientific Center Report 320 - 2096, Cambridge, Massachusetts, January 1974 .

XRM implements homogeneous flat files on top of RAM Isee Lorie/Symonds).

112. Lum, V. Y. Multi-attribute Retrieval with Combined Indexes. CACM 13, $660-665,1970$.

113. Lum, $\mathrm{V} . \mathrm{Y}$. , Yuen, $\mathrm{P} . \mathrm{S} . \mathrm{T}$. , and Dodd, M. Key to Address Transform Techniques, a Fundamental Performance Study on Large Exist- 
ing Formatted Eles. CACM 14, vol. 4, 1971.

Containg a survey and evaluations of hashing techniques as applied to large data sets.

114. Lum, V. $Y$. and Leng, H. An Optimization Problem on the Selection of Secondary Keys. Proc. $1971 \mathrm{ACM}$ Natl. Conf., vol. 26, 349 $-356,1971$.

One of the earlier investigations into the problem considered by Cardenas and others.

115. Lum, V. T. General Performance Analysis of Key-To-Address Transformation Methods Usting an Abstract File Concept. CACM 16, $603-$ $612,1973$.

116. Lum, V. Y. Senko, M. E. Wang, C. P., and Ling, H. A Cost Oriented Algorithm for Data Set Allocation in Storage Hierarchies. CACM 18, $318-322,1975$.

A cost function combining the cost of storage, CPU, channel etc. is defined and an algorithm for data set allocation is outlined, wich minimizes this cost.

117. Maruyama, q and $_{\text {. }}$ Smith, $S$. E. Analysis of Design Alternatives for Virtual Memory Indexes. IBM Research Report RC 5087 , Cct. 1974.

A number of implementation alternatives for indexes organized as B-trees are analyzed resulting into formulas, which are numerically evaluated.

118. Mauper, W. D* and Lewis, T. G. Hash Table Methods. ACM Computing Surveys $7,5-19,1975$.

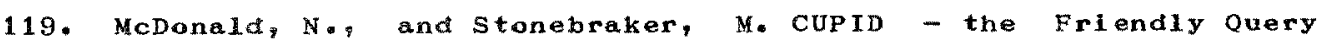
Language. ACM Pacific Conterence, San Francisco, April 1975 , ACM, New Yorx; 1975 .

CUPID is a grahic, data flow diagram-like language to the INGRES system. See also Held.

120. McGee W. C. Generallzed File processing. Annual Review in Automatic Programing vol. 5, Pergamon Press, 1969.

121. McGee, W. C. File Structures Por Generalized Data Management. Information Processing 68, 1233 - 1239, North Holland, Amster- 
dam, 1968

Introduces graphs as conceptual models for stored information.

122. McGee, $W$. C. A Contribution to the Study of Data Equivalence. Data Base Management. Proc. IfIP Work. Conf. Cargese, Corsica, April 1974, North Holland, Amsterdam, 1974.

The author presents a number of equivalent organizations in the class of homogeneous flat file (CRM) organizations and of data description language (DBTG) organizations.

123. McGee, W. C. File Level Operations on Network Data structures. ACM SIGMOD 1975 Int1. Conference, Proc., ACM, New York, 1975. The paper outines requirements and a proposal for a data manipualtion language operating on network data structures.

124. Mealey, G. H. Another Look at Data. Proc. AFIPS 1967 FJCC 525534,1967 .

One of the earlier papers proposing to view information as sets and relations between sets.

125. Mehl, J. W., and Wang, C. P. A study of Order Transformations of Hierarchic Structures in IMS Data Bases. 1974 ACM SIGFIDET Workshop, ACM, New York, 1974.

A proposal to increase the data independence supported by IMS with the help of compiled routines, which intercept the communication between application program and data management.

126. Merten, A. G., and Fry, J. P. A Data Description Language Approach to File Translation. 1974 ACM SIGFIDET Workshop, ACM, New York, 1974 .

Describes the idea and design behind the University of Michigan data translation project.

127. Merten, A. G., and Severance, D. G. Performance Evaluation File of Organizations through Modeling. Proc. ACM 1972 Natl. Conf., ACM, New York, 1972

128. Meyer, $B *$ and Schneider, H. J. Predicate Logic and Data Base Technology. Course Notes, University of Berlin, available from the authors.

Reviews predicate logic and its use as a model for man-machine interface like in Codd's work and in natural language question- 
answering systems.

129. Minsky, $N$ * On Interaction with Data Bases. 1974 ACM SIGFIDET Workshop, ACM, New York, 1974 .

The author discusses concepts, integrity rules, user views etc. He proposes a constructive approach to integrity by defining "consistent operators" to be used as primitives for more complex operations.

130. Mulin, $J$. M. An Improved Index Sequential Access Method uslng Hashed Overflow. CACM 15, 301-307, 1972.

131. Mylopoulos, J., Schuster, S., and Tsichritzis, D. A Multilevel Relational System. 1975 AFIPS NCC Proc. vol.44, 403-408, 1975.

The mechanism used in the development of the prototype system ZETA/TORUS are described. ZETA is a relational data management system with a definition capability to define a high level query language on top of lower level primitives. TORus is bulit on ZETA as an "intelifgent" natural language interface.

132. Nakamura, F., Yoshida, I., and Kondo, H. A Simulation Model for Data Base System Performance Evaluation. 1975 AfIPS NCC Proc. vol. 44, 459-463, 1975.

Description of experiments simulating the processes within a data base management system in a conventional simulation package.

133. Navathe, S. B., and Mexten, A. G. Investigation into the Application of the Relational Model to Data Translation. ACM SIGMOD 1975 Intl. Conf. Proc., $123-138$.

The paper concludes that Codd's relational model ". poses serious problems when used in the context of data translation as a vehicle for more powerful restructuring".

134. Neuhold: E. J. Data Mapping: A Formal Hierarchical and Relational View. University of Karlsruhe, Forschungsberichte, Bericht 10. February 1973.

The paper compares hierarchical and relational data models in formal notation. In particular, it makes clear that the relathonal adel is a special case of the hierarchical model. 
135. Nievergelt, J. Binary Search Trees and File Organization. ACM Computing Surveys $6,3,1974$.

136. Notley, M. G. The Peterlee IS/I System. IBM UR, Peterlee, Report $\mathrm{UK}-\mathrm{SC} 0018$.

Describes IS/I, one of the earlier Codd relational implementations.

137. Olson, C. A. Random Access File Organization for Indirectly Accessed Records. Proc. of 1969 ACM Natl. Conf. ACM, New York, 1969.

138. Owens, P. J. Phase II - a Data Base Management Modeling System. Information Processing 71, 827 - 832, North Holland, Amsterdam, 1972 .

Phase $I I$ is a modeling tool desiened specificaliy for data management evaluation.

139. Palermo, F. P. A Quantitative Approach to the Selection of Secondary Indexes. IBM Research Report RJ 0730, July 1970.

One of the earlier papers on index selection. See cardenas for recent results.

140. Palermo, F. P. A Data Base Search Problen. IBM Research Report RJ 1072, July 1972 .

The paper contains one of the earlier optimizing reduction algorithms for queries in prenicate calculus form.

141. Petrick, S. R. Semantic Interpretation in the REQUEST system. IBM Research Report RC 4457, July 1973.

REQUEST is an experimental, natural language question answering system.

142. Ramirez, J. A., RIn, N. A., and Prywes, N. S. Automatic Generation of Data Conversion Programs using a Data Description Language. 1974 ACM SIGFIDET Workshop, ACM, New York, 1974. Describes an implementation of a data definition language foue to D. P. Smith), which compiles data definitions into data translating programs.

143. Reisner, P., Boyce, R. F., and Chamberlin, D, P, Human Factors Evaluation of two Data Base Query Languages - SOUARE and SE- 
QUEL. 1975 AFIPS NCC Proc. vol. 44, $447-452,1975$. A psychological experiment with 64 subjects is described and analyzed. Only nanprogramers show a slight but statistically significant dependency on the language, which differ primarily in syntax.

144. Relter, A. Data Models for Secondary Storage Representation. University of Wisconsin, MRC Report no. 1554, May 1975.

The data models are designed with the objective to be used for the performance evaluation of different implementations.

145. Rodriguez-Rosell, J., and Hildebrand, D. A Eramework for Evaluation of Data Base Systems. Proc. of ACM European Chapters International Computing Symposium 1975 .

An implemented framework for the measurement and evaluation of sequences of events at different levels of a data base system is presented. The different levels involve commands issued in the application program at the hgih end, and disk address reference traces at the low end.

146. Rothnie, J. B. and Lozano, T. Atribute Based File Organization in a Paged Memory Environment. CACM 17, 63-69, 1974.

A comblnation "multiple key hashing" and inverted file technique allowing for a reduction of the number of page fauls for multi-key-retrieval.

147. Rothnie J. B. Evaluating Inter-Entry Retrieval Expressions In a Relational Date Base Management System. 1975 AFIPS NCC Proc. vol. 44, 417-423, 1975 .

The employed strategy attempts to utilize the linformation gained with every tuple-access for the purpose of optimization.

148. Sayani, R. H. Restart and Recovery in a Transaction Oriented Information processing System. 1974 ACM STGFIDET Vorkshop, ACM, New York, 1974 .

Restart and recovery policles are defined and discussed. The athor puts emphesis on performance.

149. Schauer, U. Ein Systen zur interaktiven Bearbeitung umfangreicher Messdaten. IBM Germany, Informatik Symposium 1975, Bad Homburg. To appear as Lecture Notes in Computer Science, Springer Verlag, Heidelberg. 
Introduces an interactive measurement data base system combining interactive computational facilities (APL), a relational data storage, a graphics oriented data manipulation language like "query by example", see zloof) with access to an open ended library of PL/I or FORTRAN subroutines. See also /13/.

150. Schkolnick, M. Secondary Index Optimization. ACM SIGMOD 1975 Intern. Conf. on Mgmt. of Data, San Jose, 1975.

See also Cardenas for similar research.

151. Schmid, H. A., and Swenson, J. R. On the Semantics of the Relational Data Model. ACM SIGMOD 1975 Intl- Conf. on Mgmt. of Data, San Jose, 1975 .

The authors are concerned with the gap between the pure formalism of Codd's relational model and the modelled part of the real world. The authors employ a kind of graph model to fill the gap.

152. Schmutz, H. Parenthesis Regular Languages and Relations. IBM Germany, Heidelberg Scientific Center, Technical Report 74.10.004, Oct. 1974.

A special form of context-free gramars is used to describe the schema to a hierarchical data model. Pair grammars are used to describe the mapping between conceptual and internal or external view. The described system is a model for a theoretical treatment of important problems in data base systems.

153. Schnelder, G. M*, and Deasautels, E. J. Creation of a File Translation Language for Networks. Information Systems $1,23-$ 31,1975 .

The authors propose a language for data translation in a network such as the ARPA network.

154. Senko, M. E., Lum, V. Y., and Owens, P. J. A File Organization Evaluation Model (FOREM). Information Processing 68, $514-519$, 1968. North Holland, Amsterdam, 1969.

FOREM is an evaluation and simulation tool specifically designed to evaluate data management systems.

155. Senko, M. E. Altman, E. B., Astrahan, M. M., and Fehder, F. L. Data structures and Accessing in Data Base systems. IBM Systems Journ. $12,30-93,1973$. 
This paper describes the thoughts and ideas behind the DIAM system, one of the eariler comprehensive approaches to data base research systems.

156. Senko, Me E. Intormation Systems: Records, Relations, Sets, Entitles and Things. Inform. Systems 1, $3-13,1975$.

157. Senko, $M$. E. Data Description Language in the Context of a Multilevel structured Description - DIAM II with FORAL. IBM Research Report RC 5073; Oct. 1973 .

158. Senko, M. E. An Introduction to FORAL for Users. IBM Research Report RC 5263, 1975 .

159. Senko, M. E. Specification of Stored Data Structures and Desired output Results in DIAM II with FORAL. Proc. of the Int. Conference on Very Large Data Hases, Boston, 1975, available from ACM.

The last three references introduce DIAM $I I$, a proposed system, which is based on binary associations and has FORAL as its query language.

160. Severance, D. G. Identifier Search Mechanism: A Survey and Generalized Model. ACM Computing Surveys 6, 3, 1974.

161. Severance, D. G. A Parametric Model of Alternative File Structures. Inform. Systems 1, 51-55, 1975.

A scheme is described, which maps a "two dimensional space ot parameterg" to a set of data organizations including well-known conventional organizations as special case.

162. Shneiderman, B. Optimum Data Base Reorganization Points. CACM 16, $362-365,1973$.

163. Shnelderman, B*, and Scheuermann, P. Structured Data Structures. CACM 17, 566-577, 1974.

The paper describes an approach to deal with integrity in case of cerain classes of data structures.

164. Shneiderman. B. A Model for opthizing Indexed File structures. IJCrs $3,93-103,1974$.

The paper is concerned with the selection of index size at dif- 
ferent levels to improve performance.

165. Shu, N. C., Housel, B. C., and Lum, V. Y. CONVERT a High level Translation Definition Language for Data Conversion. CACM 18 , $557-567,1975$.

A companion paper to Housel et al.

166. Sibley, E. H., and Taylor, R. W. A Data Definition and Mapping Language. CACM 16, 750 - 759, 1973 .

The paper discusses goals of a data definition language and illustrates data definition and mapping by examples.

167. Sibley, E. H. On the Equivalence of Data Based Systems. 1s74 ACM SIGFIDET Workshop, ACM, New York, 1974.

The two philosophical dixections, "relational" (Codd) and the "data structured" or "procedural" (DBTG) are compared. Also data translation with its connection to data restructuring and data independence is discussed.

168. Sibley, E. H., and Sayani, H. H. Data Element Dictionaries for the Information Systems Interface. NBS-Report, 1974. A discussion of the need for and objectives of a Data Dictionary capability.

169. Smith, D. P. An Approach to Data Description and Conversion. PH. D. dissertation, University of Pennsylvania, 1971. One of the earlier data definttion and mapping languages. See also Ramirez.

170. Smith, S. E. and Mommens, J. H. Automatic Generation of Physical Data Base Structures. ACM SIGMOD 1975 Intl. Conf. San Jose, 1975 .

A prototype design aid is described which generates from descriptive input rus physical data structure definitions taking into account constraints and objective functions.

171. Stahl, F. A. A Homophonic Cipher for Computational Cryptograhy. AFIPS NCC Proc. vol. $42,565-568,1973$.

172. Steel, $\mathrm{I}$. B. Data Base Standardization - A Status Report. ACM SIGMOD 1975 Int1. Conf. on Ngmt. of Data, San Jose, 1975. 
173. Steuert, J., and Goldman, J. The Relational Data Management system: A Perspective 1974 ACM SIGFIDET Workshop, ACM, New York, 1974.

An introductory description of RDMS, a system being used at MIT and based on Codd's relational model.

174. Stonebrakers $M$. The Cholce of Partial Inversions and Combined Incices. IJCYS 3, $167-188,1974$ *

see also Cardenas for rasearch on this topic.

175. Stonebraker, $M$. A Eunctional View of Data Independence. 1874 ACM SIGFIDET Workshop Proc., ACM, New York, 1974.

The paper firet analyzes the problem with a promising formal approach, which unfortunately is not kept through up to the end. It describes the types of data independence to be provided in INGRES.

176. Stonebraker, M. rmplementation of Integrity constraints and Views by Query Moditication. ACM SIGMoD 1975 Inti. Conf. Proc., San Jose, 1975.

Describes the INGRES approach to integrity in more detail. See aso Held et al.

177. Su, S. Y. W. anr Lam, H. A Semiautomatic Data Base Translation system for Achieving Data Sharing in a Netrork Environment. 1974 ACM SIGFIDET Workshop, ACM, New York, 1974.

178. Sundgren, B. Conceptual Foundation of the Infological Approach to Data Base. Data Base Management Proc. of IFIP Work. Conf. Cargese, Corsica, April 1974. Nowth Holland, Amsterdam, 1974. The lnfological approach is a kind of a conceptual data model philosophy. It may have a corresponding datalogical approach assoclated with it, which deals ith internal data forms.

179. Taylor, R. W. Generalized Data Base Management System Data Structures and their Mapping to Physical storage. Ph. D. dissertation, Univesity of Michigan, Ann Arbor, 1971. Contains a proposal for a data definition arid mapping language, which is being used in the Michigan data translation experiments. See Merten/Fry.

180. Taylor, $R$. W. Data Administration and the DBTG Report. 1974 ACM 
SIGFIDET Workshop Proc., ACM, New York, 1974.

Among others, the author proposes to use a preprocessor to obtain data independence at precompile time.

181. Taylor, R. W., and Stemple, D. W. On the Development of Data Base Editions. Data Base Management, Proc. of IFIP Work. Conf. Cargese, Corslca, April 1974. North Holland, Amsterdam, 1974. The authors' concern is the evolution of a data base at a user installetion and its impact on programs.

182. Teichroew, D. An Approach to Research in File Organization. Proc. of the 1971 SIGTR Symposium on Information, Storage and Retrievel, ACN, New York, 1971.

The essential message in this paper: there is no absolutely best representation of information. Changes as a function of knowledge about the future use of the data have to be made with assistance of the computer.

183. Thomas, J. C., and Gould, J. P. A Psychological Study of Query by Example. 1975 AFIPS NCC Proc. vol. 44, 499-445, 1975. Reports the results of an experiment with 35 subjects, who were given questions in English to be translated into query by example (see zloof).

184. Thompson, F. B., Lockemann, P. C., Dostert, B., and deverill, R. S. REL: A Rapidiy Extensible Language System. ACM 1969 Natl. Conf. Proc., $399-417,1969$.

185. Todd, S. J. P. PRTV: A Technical overview. IBM UKSC Peterlee, Technical Report UxSC 0075, 1975 .

A new description of the experimental system Is/1.

186. Tsichritzis, $P$. A Network Framework for Relation Implementation. University of Toronto, Technical Report CSRG-49, February 1975. Discusses how Codd's relational model can be implemented on top of physical networks (1.e. Iinked structures).

187. Turn, R., and Shapiro, N. Z. Privacy and Security In Data Bank Systems - Measures of Effectiveness, Costs and Protection-Intruder Interactions. AfIPS 1972 FJCC, vol. $41,435-444$.

188. Van der Pool, J. A. Optimum Storage Allocation for a File in 
Steady State. I BM J. Res. DIV. 17, $27-38,1973$.

Files with bey-to-address transformations (hashing) and with overflow areas are analyzed. Storege utilization, overflow rate and other relevant factors are given for the steady state.

189. Vose, $M$. R. and Rlchardson, J. S. An Approach to Inverted Index Malntenance. Comp. Bull. 16, May 1972.

190. Wang, C. P., end Wedekind, H.H. Segment Synthesis in Logical Data Base Design. IBM J. Res. Dev, 19,71-77, 1975.

The authors specify a minimal cover algorithm, which calculates a set of minimal covers to a eiven set of relations with transitive dependencies. Each minimal cover is again a set of relatons whout transitive dependencies. Given the minimum cover, a set of relations in Codt's third normal form can easily be constructed.

191. Wedekind, H. Datenorganisation. de Gruyter, Ber1in, 1972.

192. Wedekind, H. Datenbanksysteme I. Bibliographisches Institut Mannhein, 1974 .

193. Wedekind, $H$. On the Selection at Access Paths in a Data Base System. Data Base Management, Proc. of IFIP Work. Conf., Cargese, Corsica, April 1974. North Holland, Amsterdam, 1974. The paper's concern is modeling and analysis for the determination of eficient access paths.

194. Welís, M. E., Katke, W., Olson, J*, and Yang, S. C. SIMS- an Integrated, User-oriented Information System. AFIPS FJCC 1972 , val. $41,1117-1131,1972$.

SIMS ls interesting for a number of reasons. It offers a high level data definition, mapping and manipulation language. Data on normal files may be mapped to a conceptual high level hierarchical fom ant used in the query language. Particular attention has beer pald to transferability of data and programs.

195. Wong, E., and Chiang, T. C. Canonical structure in Attribute Based File organizations. CACM 14, 593-597, 1971.

Each query is assumed to be a boolean expression over elementary queries. In this case the data başe can be organized according to the elementary querles and access becomes essentially the 
problem of putting a boolean expression into some standard form.

196. Yao, S. H. Evaluation and Optimization of File organization through Analytic Modeling. Ph. D. dissertation, University of Michigan, 1974 .

197. Yue, P. C., and Wong, C. X. Storage Cost Considerations in Secondary Index Selection. IBM Research Report RC 5070, to appear aso in IJCIS.

For other recent results in this area of research see Cardenas.

198. Zloof, M. M. Query By Example. 1975 AFIPS NCC Proc. vol. 44, $431-437,1975$.

The basic features of query by example are lilustrated. The user's perception of data processing in this query language is that of manipulating tables in a graphicaliy pre-established frame of reference consisting of table skeletons, into which the user fills information. 